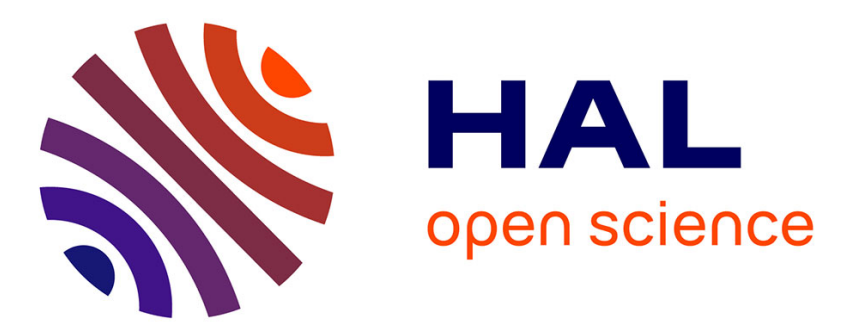

\title{
Thermodynamic analysis of glass-forming ability in a Ca-Mg-Zn ternary alloy system
}

\author{
Stéphane Gorsse, Glenn Orveillon, Oleg N. Senkov, D. B. Miracle
}

\section{To cite this version:}

Stéphane Gorsse, Glenn Orveillon, Oleg N. Senkov, D. B. Miracle. Thermodynamic analysis of glassforming ability in a Ca-Mg-Zn ternary alloy system. Physical Review B: Condensed Matter and Materials Physics (1998-2015), 2006, 73, n (22), 224202 (9 p.). 10.1103/PhysRevB.73.224202 . hal00084006

\section{HAL Id: hal-00084006 https://hal.science/hal-00084006}

Submitted on 5 Jul 2006

HAL is a multi-disciplinary open access archive for the deposit and dissemination of scientific research documents, whether they are published or not. The documents may come from teaching and research institutions in France or abroad, or from public or private research centers.
L'archive ouverte pluridisciplinaire HAL, est destinée au dépôt et à la diffusion de documents scientifiques de niveau recherche, publiés ou non, émanant des établissements d'enseignement et de recherche français ou étrangers, des laboratoires publics ou privés. 


\title{
Thermodynamic Analysis of Glass Forming Ability in a Ca-Mg-Zn Ternary
}

\author{
Alloy System \\ S. Gorsse ${ }^{1, *}$, G. Orveillon ${ }^{1}$, O.N. Senkov ${ }^{2}$, D.B. Miracle ${ }^{3}$ \\ ${ }^{1}$ Institut de Chimie de la Matière Condensée de Bordeaux ICMCB-CNRS and ENSCPB, \\ Université Bordeaux I, 87, Av. Dr A.Schweitzer, 33608 PESSAC Cedex, France \\ ${ }^{2}$ UES, Inc., 4401 Dayton-Xenia Road, Dayton, Ohio 45432-1894, USA \\ ${ }^{3}$ Air Force Research Laboratory, Materials and Manufacturing Directorate, Wright-Patterson \\ AFB, Ohio 45433, USA \\ *: Corresponding author
}

\begin{abstract}
A thermodynamic analysis of the onset driving force for crystallization of super-cooled liquid has been conducted to explain strong composition dependency of the glass forming ability in the CaMg-Zn ternary alloy system observed experimentally. In addition to the onset driving force, other energetic and kinetic factors are discussed to explain the observed glass stabilities. The universality of this method is discussed, thus establishing an analytic approach for determining the most stable glass in a given alloy system.
\end{abstract}

Keywords: Ca-Mg-Zn alloys; Bulk amorphous metals; Crystallization; Thermodynamics. 


\section{Introduction}

Ca-Mg-Zn bulk metallic glasses are relatively new class of amorphous alloys. The first bulk glassy alloys in this system, $\mathrm{Ca}_{64} \mathrm{Mg}_{15} \mathrm{Zn}_{21}, \mathrm{Ca}_{60} \mathrm{Mg}_{16} \mathrm{Zn}_{24}$ and $\mathrm{Ca}_{55} \mathrm{Mg}_{18} \mathrm{Zn}_{27}$, were reported by Senkov and Scott in 2003 [1], and after that several other compositions were reported and their glass forming ability and thermal stability were analyzed in detail [2-6]. The Ca-Mg-Zn bulk metallic glasses have unique properties, such as low density $(\sim 2.0 \mathrm{~g} / \mathrm{cc})$, low Young's modulus ( 17-20 GPa) comparable to the modulus of human bones, low glass transition temperature $\left(\mathrm{T}_{\mathrm{g}} \sim 100^{\circ} \mathrm{C}\right)$ and a wide temperature range of super-cooled liquid $\left(\Delta \mathrm{T}_{\mathrm{xg}}=\mathrm{T}_{\mathrm{x}}-\mathrm{T}_{\mathrm{g}} \sim 30-70^{\circ} \mathrm{C}\right)$. The elements are fully biocompatible making these alloys attractive for use in biomedical applications. While most Ca-based crystalline alloys are reactive and oxidize in air in a matter of days, these Ca-based metallic glasses have much better oxidation resistance and retain shiny surfaces long after casting. Corrosion resistance of some of these glassy alloys is comparable to that of Fe-based bulk metallic glasses and Mg-based crystalline alloys [7]. It is also noteworthy that this ternary metallic glass system is based on two simple metals, $\mathrm{Ca}$ and $\mathrm{Mg}$, which distinguishes the Ca-Mg-Zn system from transition metal based bulk metallic glasses [8].

Recently the glass forming ability (GFA) of ternary Ca-Mg-Zn bulk glassy alloys was experimentally analyzed as a function of alloy composition [6], and the maximum (or critical) thickness, $\lambda$, at which the alloy plates are fully amorphous after copper mold casting was found to be very sensitive to alloy composition. In particular, alloys with compositions located in the $\mathrm{CaMg}_{2}$ phase field of the liquidus projection had much better glass forming ability than alloys located in the $\mathrm{CaZn}_{2}$ or $\mathrm{Ca}$ phase fields. It was suggested that the difference in behavior can be due to different kinetics of crystallization of these phases, so that the easier formation of $\mathrm{Ca}$ and $\mathrm{CaZn}_{2}$ crystal phases during solidification does not allow significant liquid undercooling and 
glass formation during copper mold casting [6]. However, the relationship between GFA and liquid composition remains unclear. This work aims to explain the compositional dependence of the GFA of Ca-Mg-Zn liquid.

Several approaches have been proposed to assess GFA [9-11]. They are mainly based on the assumption that the nucleation and growth of the competing crystalline phases are the only events that prevent amorphization, so that the influence of the liquid composition on GFA can be analysed in terms of precipitation kinetics of the solid phases from the undercooled liquid. According to classical nucleation theory, the steady-state nucleation rate of a new phase decreases exponentially with an increase in the height of the nucleation energy barrier. This quantity, which represents the work required to form one critical nucleus, depends on the solid/liquid interfacial energy and the chemical driving force for nucleation, and is the dominant factor that controls nucleation kinetics. As examples, Zhu et al. $[9,10]$ have calculated the time necessary to form a crystal phase in the undercooled liquid, and Tokunaga et al. [11] have calculated the critical cooling rates required to avoid crystallization in the liquid. In these approaches, the glass forming range (GFR) was correlated with composition ranges with relatively longer reduced times of formation of crystalline phases [10] or lower critical cooling rates to avoid crystallization [11]. These thermodynamic and quasi-kinetic calculations were conducted using CALPHAD databases that describe the undercooled liquid as a disordered phase. Such phenomenological models of the liquid, expressed using mathematical representation of experimental data generally obtained at equilibrium, are convenient since they are widely available. However, this approach offers only qualitative insight for calculations performed outside the range where experimental data are available for optimization of the Gibbs energy parameters. In consequence, most available CALPHAD databases describing the liquid as a random solution are not capable of representing the thermodynamic properties of the liquid in a 
physically complete way. Hakenberg et al. [12] suggest that calculations made by extrapolation of G-X or G-T curves provide values that should be considered only from a qualitative or semiquantitative point of view.

The most recent picture of a supercooled liquid describes locally favoured structure embedded in a normal random liquid $[13,14]$. Such short range ordering (SRO) in the liquid gives rise to an excess of heat capacity upon cooling to $\mathrm{T}_{\mathrm{g}}[15]$ and tends to stabilize the undercooled liquid $[16,17]$. As a result, driving forces for nucleation of the crystalline phases are lowered. To take this effect into account, Palumbo et al. [18] added a $\mathrm{T}^{-1}$ term in the expression of the random solution model representing the interaction parameters of the Gibbs free energy of the liquid. However, data from to the undercooled liquid has to be obtained to assess or reassess existing thermodynamic descriptions. As demonstrated by Agren et al. [19], reference states of the liquid phase components different from SGTE-Dinsdale [20] must be used to avoid unphysical $\mathrm{C}_{\mathrm{p}}$ curves. This is especially true when melting points of the components differ strongly, such as in the Ca-Mg-Zn system where $T_{m}(Z n)$ is half of $T_{m}(C a)$.

In the present work, a thermodynamic analysis of the driving force for crystallization of the various phases in under-cooled $\mathrm{Ca}-\mathrm{Mg}$ - $\mathrm{Zn}$ liquids was conducted to explain the compositional dependence of GFA. We use a computational thermodynamic model recently developed for the Ca-Mg-Zn system [21] to calculate the driving forces for nucleation of crystalline phases. Given the difficulty in representing SRO tendency in liquids with significant difference in melting temperature of the constituents, the effect of SRO in the liquid on the GFA is analysed via the fragility concept introduced by Angell [22]. After presenting the thermodynamic description of the Ca-Mg-Zn system, the method to calculate driving forces and the experimental procedure to produce glassy alloys, we discuss our results and analyze how GFA is related to the 
crystallization driving force and the ordering tendency of the liquid. Results are also discussed in regards to the efficient cluster packing structural model [23].

\section{Computational and experimental procedures}

\subsection{Thermodynamic calculations}

The thermodynamic calculations were conducted using critically assessed thermodynamic parameters [21], based on the CALPHAD method [24]. In the assessment performed by Brubaker et al. [21], the Ca-Mg-Zn system consists of four solution phases (fcc, hcp and bcc terminal solid solutions, and liquid), fourteen binary compounds $\left(\mathrm{Ca}_{3} \mathrm{Zn}, \mathrm{Ca}_{5} \mathrm{Zn}_{3}, \mathrm{CaZn}, \mathrm{CaZn} \mathrm{CaZn}_{3}, \mathrm{CaZn}\right.$, $\mathrm{CaZn}_{11}, \mathrm{CaZn}_{13}, \mathrm{CaMg}_{2}, \mathrm{MgZn}_{2}, \mathrm{Mg}_{2} \mathrm{Zn}_{11}, \mathrm{Mg}_{2} \mathrm{Zn}_{3}, \mathrm{Mg}_{7} \mathrm{Zn}_{3}$ and $\mathrm{MgZn}$ ) and one ternary compound $\left(\mathrm{Ca}_{2} \mathrm{Mg}_{6} \mathrm{Zn}_{3}\right)$. The optimized thermodynamic parameters of the liquid phase used in this work are listed in Table A1 of the Appendix.

The stable binary intermetallic phases are treated as stoichiometric compounds with two sublattices, $(\mathrm{A})_{\mathrm{a}}(\mathrm{B})_{\mathrm{b}}$. Their molar Gibbs energy is written as:

$G_{m}^{A_{a} B_{b}}=a{ }^{0} G_{A}^{\phi}+b{ }^{0} G_{B}^{\phi}+C_{1}^{A_{a} B_{b}}+C_{2}^{A_{a} B_{b}} T$

where $\mathrm{C}_{1}$ and $\mathrm{C}_{2}$ are constants, $a$ and $b$ are the atomic fractions of $\mathrm{A}$ and $\mathrm{B}$ constituents, ${ }^{0} G_{i}^{\phi}$ is the molar Gibbs energy of a pure constituent $i$ in the $\phi$ state, and $T$ is the absolute temperature. The molar Gibbs energy of the $\mathrm{Ca}_{2} \mathrm{Mg}_{6} \mathrm{Zn}_{3}$ ternary compound is expressed as:

$G_{m}^{C a_{2} M g_{6} Z n_{3}}=2{ }^{0} G_{C a}^{f c c}+6{ }^{0} G_{M g}^{h c p}+3{ }^{0} G_{Z n}^{h c p}+C_{1}^{C a_{2} M g_{6} Z n_{3}}+C_{2}{ }^{C a_{2} M g_{6} Z n_{3}} T$

The solution phases, including the liquid, are treated as substitutional random solutions $(\mathrm{Ca}, \mathrm{Mg}$, Zn). The molar Gibbs energy of mixing is expressed by a sub-regular solution model in which 
composition dependence is based on the Redlich-Kister equation [25]. The molar Gibbs energy for a solution phase $\phi$ is given by the formula:

$G_{m}^{\phi}=x_{C a}{ }^{0} G_{C a}^{\phi}+x_{M g}{ }^{0} G_{M g}^{\phi}+x_{Z n}{ }^{0} G_{Z n}^{\phi}+R T\left(x_{C a} \ln x_{C a}+x_{M g} \ln x_{M g}+x_{Z n} \ln x_{Z n}\right)+{ }^{x s} G_{m}^{\phi}$

and

$$
{ }^{x s} G_{m}^{\phi}=x_{C a} x_{M g} \sum_{v=0}^{n}{ }^{v} L_{C a, M g}^{\phi}\left(x_{C a}-x_{M g}\right)^{v}+x_{C a} x_{Z n} \sum_{v=0}^{n}{ }^{v} L_{C a, Z n}^{\phi}\left(x_{C a}-x_{Z n}\right)^{v}
$$

$$
+x_{M g} x_{Z n} \sum_{v=0}^{n}{ }^{v} L_{M g, Z n}^{\phi}\left(x_{M g}-x_{Z n}\right)^{v}+x_{C a} x_{M g} x_{Z n} \sum_{v^{\prime}=0}^{n}{ }^{v^{\prime}} L_{C a, M g, Z n}^{\phi} x_{v^{\prime}}
$$

where ${ }^{x s} G^{\phi}$ is the contribution of the non-ideal interactions between the components; $x_{i}$ is the mole fraction of the constituent $i .{ }^{v} L_{i, j}^{\phi}$ represents the $v^{\text {th }}$-order binary interaction parameter and is expressed as: ${ }^{v} L_{i, j}^{L}={ }^{v} A^{\phi}+{ }^{v} B^{\phi} T$, where ${ }^{v} A^{\phi}$ and ${ }^{v} B^{\phi}$ are constants. ${ }^{v^{\prime}} L_{C a, M g, Z n}^{\phi}$ is the excess ternary interaction parameter, depending on the value of the coefficient $v^{\prime}-0,1,2$ - respectively for the contribution of $\mathrm{Ca}, \mathrm{Mg}$ and $\mathrm{Zn}$.

The method used to calculate the onset driving forces of various crystalline phases was described by Hillert [26] and is illustrated in Figure 1. The onset driving forces associated with the beginning of the precipitation of a given compound $\varepsilon\left(\mathrm{ODF}^{\varepsilon}\right)$ and solid solution $\alpha\left(\mathrm{ODF}^{\alpha}\right)$ from an undercooled liquid with composition $x_{B}^{L}$, are shown as vertical arrows in Figure 1 and can be written for the $\alpha$ phase for example as:

$$
\begin{aligned}
& O D F^{\alpha}=x_{A}^{\alpha} \cdot G_{A}^{L}\left(x_{B}^{L}\right)+x_{B}^{\alpha} \cdot G_{B}^{L}\left(x_{B}^{L}\right)-G_{m}^{\alpha}\left(x_{B}^{\alpha}\right) \\
& \text { or } O D F^{\alpha}=G_{m}^{L}\left(x_{B}^{L}\right)+\left(\partial G_{m}^{L} / \partial x^{L}\right)_{x_{B}^{L}}\left(x_{B}^{\alpha}-x_{B}^{L}\right)-G_{m}^{\alpha}\left(x_{B}^{\alpha}\right)
\end{aligned}
$$

The ODF's were calculated at $\mathrm{T}=390 \mathrm{~K}$ which represents the average $\mathrm{T}_{\mathrm{g}}$ for the Ca-Mg-Zn alloys studied in the present work. Authors want to stress that the numerical values of the onset driving forces (ODF) are semi-quantitative. In consequence, calculating the ODF near $\mathrm{T}_{\mathrm{g}}$ or in the 
proximity of the equilibrium state and then extrapolating down to $T_{g}$ leads to similar results from a semi-quantitative point of view.

\subsection{Experimental procedure}

The Ca-Mg-Zn alloys were prepared by mixing and induction melting of $99.9 \%$ pure elements. The prepared alloys were induction re-melted in a quartz crucible and the molten metal was ejected from a hole at the bottom of the crucible into a water cooled copper mold with step-like or wedge-like cavities. The step-like samples had $10 \mathrm{~mm}$ width, $50 \mathrm{~mm}$ length, and graded thicknesses of $2 \mathrm{~mm}, 4 \mathrm{~mm}, 6 \mathrm{~mm}, 8 \mathrm{~mm}$ and $10 \mathrm{~mm}$. The wedge-like samples had two different configurations; i.e. some samples were $10 \mathrm{~mm}$ wide, $50 \mathrm{~mm}$ long and their thickness varied from $2 \mathrm{~mm}$ to $10 \mathrm{~mm}$, while other samples were $6 \mathrm{~mm}$ wide, $30 \mathrm{~mm}$ long and their thickness varied from $0.5 \mathrm{~mm}$ to $3 \mathrm{~mm}$. The samples were cut in pieces of different thicknesses and their amorphous state and maximum (critical) thicknesses at which the alloys remained fully amorphous after the copper mold casting were examined using X-ray diffraction (XRD) and differential scanning calorimetry (DSC) following a procedure described in detail elsewhere [6]. The compositions of the produced alloys, as well as their critical thicknesses, $\lambda$, glass transition, crystallization, solidus and liquidus temperatures, are given in Table 1.

\section{$\underline{\text { 3. Results and discussion }}$}

Figure 2 shows the onset driving forces (ODF's) calculated using the CALPHAD database for the primary crystallization of various possible phases from the undercooled liquid in $\mathrm{Ca}_{55} \mathrm{Mg}_{\mathrm{X}} \mathrm{Zn}_{100-\mathrm{X}}$ alloys, where $\mathrm{X}=0$ to 40 at.\%. The ODF's were calculated at $\mathrm{T}=390 \mathrm{~K}$ (close to the average $\mathrm{T}_{\mathrm{g}}$ for the Ca-Mg-Zn alloys studied in the present work) as a function of the $\mathrm{Mg}$ content. These 
calculations show that in the given composition range three phases, $\mathrm{CaZn} 2, \mathrm{CaZn}$ and $\mathrm{CaMg}_{2}$, exhibit the highest driving force for crystallization from the undercooled liquid at $390 \mathrm{~K}$. It can also be seen in Figure 2 that, with varying Mg content from 0 to 40 at.\%, the driving forces of the crystalline phases show a local minimum at $\mathrm{X} \approx 19 \mathrm{at} . \%\left(\mathrm{Ca}_{55} \mathrm{Mg}_{19} \mathrm{Zn}_{26}\right)$. A smaller ODF value generally indicates a higher crystallization resistance or a better ability for glass formation $[27,28]$. Therefore, according to this criterion, the $\mathrm{Ca}_{55} \mathrm{Mg}_{19} \mathrm{Zn}_{26}$ alloy must have the best GFA in the $\mathrm{Ca}_{55} \mathrm{Mg}_{\mathrm{X}} \mathrm{Zn}_{100-\mathrm{X}}$ alloy series $(\mathrm{X}=0-40)$. This conclusion agrees well with the experimental results (see Table 1). Indeed, among three experimental alloys in this composition line (i.e. $\mathrm{Ca}_{55} \mathrm{Mg}_{15} \mathrm{Zn}_{30}, \mathrm{Ca}_{55} \mathrm{Mg}_{20} \mathrm{Zn}_{25}$ and $\mathrm{Ca}_{55} \mathrm{Mg}_{25} \mathrm{Zn}_{20}$ ), the composition of the $\mathrm{Ca}_{55} \mathrm{Mg}_{20} \mathrm{Zn}_{25}$ alloy is very close to the local minimum of the ODF's, and this alloy exhibits the highest GFA with the critical thickness of $2 \mathrm{~mm}$, whereas $\mathrm{Ca}_{55} \mathrm{Mg}_{15} \mathrm{Zn}_{30}$ and $\mathrm{Ca}_{55} \mathrm{Mg}_{25} \mathrm{Zn}_{20}$ alloys have the critical thickness of 0.5 and $1 \mathrm{~mm}$, respectively (see Figure 2).

Similar results were obtained for alloys of $\mathrm{Ca}_{60} \mathrm{Mg}_{X} \mathrm{Zn}_{100-\mathrm{X}}$ and $\mathrm{Ca}_{100-\mathrm{X}} \mathrm{Mg}_{\mathrm{X}} \mathrm{Zn}_{20}$ series. The ODF's calculated along these composition lines are represented in Figures 3 and 4, respectively. In the $\mathrm{Ca}_{60} \mathrm{Mg}_{\mathrm{X}} \mathrm{Zn}_{100-\mathrm{X}}$ system, the calculations predict that the undercooled liquid starts to crystallize by formation of two phases, $\mathrm{CaZn}$ at a lower $\mathrm{Mg}$ content $(<17.5 \%)$ and $\mathrm{CaMg}_{2}$ at a larger amount of $\mathrm{Mg}$ (see Figure 3). The local minimum of the ODF is found at $\sim 17.5 \% \mathrm{Mg}$, predicting the best GFA for the alloy $\mathrm{Ca}_{60} \mathrm{Mg}_{17.5} \mathrm{Zn}_{22.5}$ in this alloy series, in agreement with the experimental results (see Table 1 and Figure 3). Indeed, this alloy has the maximum critical thickness of $10 \mathrm{~mm}$, and the critical thickness for the $\mathrm{Ca}_{60} \mathrm{Mg}_{\mathrm{X}} \mathrm{Zn}_{100-\mathrm{X}}$ alloys decreases with an increase in the ODF.

In the $\mathrm{Ca}_{100-X} \mathrm{Mg}_{X} \mathrm{Zn}_{20}$ alloy series, three phases are predicted to form during crystallization of the undercooled liquid (see Figure 4). These are fcc-Ca (at 0-8\% Mg), $\mathrm{Ca}_{5} \mathrm{Zn}_{3}$ (at $8-16.5 \% \mathrm{Mg}$ ) and $\mathrm{CaMg}_{2}$ (at $16.5-40 \% \mathrm{Mg}$ ). The local minimum of ODF is located at $\sim 16.5 \% \mathrm{Mg}$, predicting the 
alloy $\mathrm{Ca}_{63.5} \mathrm{Mg}_{16.5} \mathrm{Zn}_{20}$ to be the best glass former in this alloy series. The experimental results appear to support this prediction by showing the best GFA for the $\mathrm{Ca}_{62.5} \mathrm{Mg}_{17.5} \mathrm{Zn}_{20}$ alloy, which composition is located near the ODF minimum (see Table 1 and Figure 4). The GFA (i.e. critical thickness $\lambda$ ) appropriately decreases in the alloys with increasing ODF values.

The present results clearly demonstrate that a local minimum of the ODF within a given composition line corresponds to an alloy composition with the best GFA (the highest critical thickness) within this composition line. Similar correlations have recently been obtained for the $\mathrm{Cu}-\mathrm{Ti}-\mathrm{Zr}$ [27] and $\mathrm{Cu}-\mathrm{Mg}-\mathrm{Y}$ [28] ternary systems, which may indicate universality of this method for predicting the alloys with good forming ability. The best GFA within a given alloy system may therefore reasonably be predicted analytically from a complete two-dimensional plot of the ODF for the full composition space provided by that alloy system (Figure 5). In addition to one minimum of the ODF for Ca-rich region, the Figure 5 indicates the presence of another ODF minimum in the Mg-rich region for the composition $\mathrm{Ca}_{4} \mathrm{Mg}_{64} \mathrm{Zn}_{32}$. Glass forming ability in this composition regime has recently been investigated by $\mathrm{Gu}$ et al. [29]. The best GFA has been found along the composition line $\mathrm{Ca}_{5} \mathrm{Mg}_{80-\mathrm{X}} \mathrm{Zn}_{15+\mathrm{X}}$. The glassy rods with a diameter of up to $4 \mathrm{~mm}$ were produced for the alloy $\mathrm{Ca}_{5} \mathrm{Mg}_{67} \mathrm{Zn}_{28}$, which is in good agreement with the calculated ODF minimum found in this composition range.

Several parameters allow evaluation of GFA from thermal behaviour of their amorphous state during reheating. The relationship between the ODF and the most widely used GFA indicators: $\alpha\left(T_{x} / T_{l}\right)[30], \mathrm{T}_{\mathrm{rg}}\left(T_{g} / T_{l}\right)[31], \mathrm{T}_{\mathrm{rgx}}\left(T_{g} T_{x} / T_{l} T_{m}\right)[6], \gamma\left(T_{x} /\left(T_{g}+T_{l}\right)\right)[32]$ and $\Delta \mathrm{T}_{\mathrm{xg}}\left(T_{x}-T_{g}\right)$ [33], for the Ca-Mg-Zn alloys are shown in Figures 6a-e together with the regression coefficients $\mathrm{R}^{2}$. Among them, the parameters $\mathrm{T}_{\mathrm{rg}}$ and $\alpha$ show the highest correlation with $\mathrm{R}^{2}$ of 0.86 and 0.80 , respectively. The parameters $\gamma$ and $T_{\text {rgx }}$ exhibit a moderate correlation characterized by $R^{2}$ of 0.74 
and 0.71 , respectively. There is no correlation found between ODF and $\Delta \mathrm{T}_{\mathrm{xg}}$. The correlation between ODF and these criteria can be summarized as: $\mathrm{T}_{\mathrm{rg}}, \alpha>\gamma, \mathrm{T}_{\mathrm{rgx}}>\Delta \mathrm{T}_{\mathrm{xg}}$.

Glass formation is a competing process between the liquid and crystalline phases, so that a reliable GFA indicator must account for the stability of the liquid phase and the competing crystalline phases. The ODF intrinsically represents this relative stability since it depends on the difference between Gibbs free energies of the liquid and crystalline phases. Among other GFA parameters, $\mathrm{T}_{\mathrm{rg}}$ measures the easiness for liquid to be undercooled into the glassy state, and $\alpha=$ $\mathrm{T}_{\mathrm{x}} / \mathrm{T}_{1}$ reflects stability of the glass against crystallization; while $\mathrm{T}_{\mathrm{rgx}}$, as a combination of the two previous parameters, takes into account both liquid and glass stability against crystallization. Similarly, the parameter $\gamma$ considers both the relative stability of the liquid against crystallisation $\left(T_{x} / T_{l}\right)$ and the stability of the glass $\left(T_{x} / T_{g}\right)$. The parameter $\Delta \mathrm{T}_{\mathrm{xg}}$ measures the resistance of the glass towards devitrification upon reheating above $T_{g}$, and so only reflects the stability of the glass. These results demonstrate the concordance between the specific GFA indicators, $\alpha, \gamma$ and $\mathrm{T}_{\mathrm{rg}}$, measured via the thermal behaviour of a glassy alloy and the ODF calculated from thermodynamic properties of the alloy. The various parameters can be evaluated only after a candidate glass is produced and so are not predictive, while the ODF in the present work provides a predictive capability.

The critical thickness $\lambda$ provides a more practical quantification of GFA. The relationship between $\lambda$ and GFA indicators for the Ca-Mg-Zn system are shown in Figures 7a-e, together with trendlines and the regression coefficient $\mathrm{R}^{2}$. Only modest correlation is obtained for $\mathrm{T}_{\mathrm{rgx}}, \gamma$ and $\alpha$ with a $\mathrm{R}^{2}$ of $0.68,0.63$ and 0.62 , respectively, followed by $T_{\mathrm{rg}}$ with $\mathrm{R}^{2}$ of $0.53 . \Delta \mathrm{T}_{\mathrm{xg}}$ exhibits no correlation with $\lambda$. The relationship between the ODF and $\lambda$ for the Ca-Mg-Zn alloys is shown in Figure $8 \mathrm{a}$. A very large scatter in $\lambda$ vs. ODF can be seen, with an overall tendency for $\lambda$ to 
increase with a decrease in the ODF. This poor correlation suggests that additional factors must be considered. Both the liquid/solid interfacial energy, which is involved in the nucleation barrier expression along with the ODF, and SRO in the liquid, can contribute to the nucleation energy barrier and crystallization kinetics of the undercooled liquid. We discuss the contributions of these additional factors below.

The Ca-Mg-Zn alloys studied here can be separated into 3 groups based on the first crystal phase to form. The first group represents 6 alloys that crystallize via formation of the $\mathrm{CaMg}_{2}$ phase, the second group consists of 4 alloys forming CaZn during the first step of crystallization; and the last group consists of 2 alloys that start to crystallize with formation of $\mathrm{Ca}_{5} \mathrm{Zn}_{3}$ (Figures 2-4). The GFA in each group increases with decreasing ODF for crystallization, and a different dependence of $\lambda$ on ODF in each group (Figure 8b) suggests that important differences exist in the nucleation barrier for the different crystal phases. A higher solid/liquid interfacial energy contributes to an increased height of the nucleation barrier and decreases the rate of nucleation at constant ODF. According to Turnbull's empirical equation [34], interfacial energy is proportional to the heat of fusion. $\mathrm{CaMg}_{2}$ has the highest heat of fusion, $\Delta \mathrm{H}_{\mathrm{f}}=16150 \mathrm{~J} / \mathrm{mol}$, compared to $\Delta \mathrm{H}_{\mathrm{f}}=10470 \mathrm{~J} / \mathrm{mol}$ for $\mathrm{CaZn}$ and $9470 \mathrm{~J} / \mathrm{mol}$ for $\mathrm{Ca}_{5} \mathrm{Zn}_{3}$. These values are consistent with higher GFA in alloys where $\mathrm{CaMg}_{2}$ is the first solid to form rather than those where $\mathrm{CaZn}$ or $\mathrm{Ca}_{5} \mathrm{Zn}_{3}$ form at the same ODF values (Figure 8b). Considering together ODF and interfacial energy via the first solid phase to form considerably reduces the scatter in $\lambda$ vs. ODF and provides correlation coefficients superior to those for any of the GFA parameters discussed earlier.

SRO may also contribute to differences in GFA of alloys with equivalent ODF values. Recent experimental investigations indicate the importance of SRO in the melt on GFA $[16,17]$. SRO lowers the total free energy of the liquid compared to the corresponding ideal liquid state with a 
random structure [14], and as a consequence reduces the thermodynamic driving force for crystallization. The two-order parameter model of Tanaka [14], which describes the liquid with locally ordered structure embedded in a normal disordered liquid, suggests that the liquid becomes more stable against crystallization with an increase in the degree of SRO (fraction of the locally favored structure). The latter can be a result of the presence of efficiently packed clusters in the amorphous structure [23,35,36]. Topological studies [23,35-38], supported by computer simulations [39], show that a set of preferred solute-to-solvent radius ratios produces efficient atomic packing at both local (nearest-neighbor atomic clusters) and medium-range length scales. This topological contribution to stability derives from an energetic term associated with reduced specific volume, and from a kinetic term by increasing viscosity and hence decreasing the rate of mass transport. The Ca-Mg-Zn system has a combination of atomic sizes sufficient to produce these efficiently packed local structures. According to the efficient cluster packing model [23], $\mathrm{Ca}-\mathrm{Mg}-\mathrm{Zn}$ glasses are represented as $<10,9>$ structures, where $\mathrm{Mg}$ solutes have $\sim 10$ nearest neighbors and $\mathrm{Zn}$ solutes have $\sim 9$ nearest neighbors. Glass compositions predicted from this model range from $\mathrm{Ca}_{70} \mathrm{Mg}_{15} \mathrm{Zn}_{15}$ to $\mathrm{Ca}_{53} \mathrm{Mg}_{12} \mathrm{Zn}_{35}$, which encompasses nearly all alloy compositions in the present work.

To compare the degree of short range order for different compositions, one can evaluate the fragility index D which characterizes the strong nature of the liquid $[33,41]$. Tanaka $[14,40]$ provides evidence for correlation between the critical cooling rate, $\mathrm{R}_{\mathrm{c}}$, required for amorphization with the fragility index $\mathrm{D}$ and the reduced glass transition temperature $\mathrm{T}_{\mathrm{rg}}$, in accord with the equation:

$-\log R_{C}=0.266 D+45.1 \frac{T_{g}}{T_{l}}-32.5$ 
Using Equation 5, the fragility indexes D were calculated as a function of liquid composition from thermal behavior of Ca-Mg-Zn glassy alloys and from $\mathrm{R}_{\mathrm{c}}$, which was calculated from the GFA parameter $\lambda$ using an empirical equations suggested by Lu and Liu [32]. The results are shown in Table 2 and Figure 9. Although alloys with the smallest $\lambda$ values of $\sim 0.5 \mathrm{~mm}$ have the lowest values of $\mathrm{D}$ consistent with fragile glasses, there is no clear correlation between $\mathrm{D}$ and $\lambda$ for alloys with $\lambda \geq 1 \mathrm{~mm}$. For these more stable alloys, D varies from 15 to 25 , which is typical for very strong liquids $[33,41]$. The high fragility indexes support the model prediction $[23,35,36]$ of a high degree of SRO (efficient atomic clusters) in the Ca-Mg-Zn alloys.

Although no direct correlations between the critical thickness, $\lambda$, and the fragility index $\mathrm{D}$ or the ODF are obtained when these parameters are considered separately (see Figures 8a and 9), combination of these parameters allows a good correlation (Figure 10). A clear dependence of $\lambda$ on ODF and D is well fitted by a plane in $\lambda$-D-ODF space, expressed by the equation:

$\log (\lambda)=0.11 D-2.28 \mathrm{ODF} / \mathrm{RT}+0.65,\left(\mathrm{R}^{2}=0.882\right)$

This result indicates that the combination of low driving forces for crystallization and strong liquid behavior results in better GFA. This is consistent with previous suggestions that improved GFA is associated with low driving forces [27,28], and that strong liquids are better glass formers [41,42]. While the GFA of alloys generally increases with a decrease in the ODF for nucleation, the solid/liquid interfacial energy and SRO must also be taken into account when comparing the GFA of different alloys. It has thus been shown here that $\mathrm{Ca}_{60} \mathrm{Mg}_{17.5} \mathrm{Zn}_{22.5}$ and $\mathrm{Ca}_{62.5} \mathrm{Mg}_{17.5} \mathrm{Zn}_{20}$ are the best glass forming alloy compositions because they combine the lowest driving forces for crystallization and strongest liquid behaviour. 


\section{Conclusions}

A thermodynamic analysis of the driving force for the onset of crystallization of different phases from the under-cooled liquid in the Ca-Mg-Zn system was conducted. A strong dependence of the driving force on the alloy composition was found and the alloys corresponding to the local minima of the onset driving force were identified. These alloys were found to have good glass forming ability, having a maximum critical thickness at which they remained fully amorphous during copper mold casting of up to $10 \mathrm{~mm}$. Although glass forming ability has a general tendency to increase with a decrease in the onset driving force, it is also enhanced with an increase in the liquid/solid interface energy of a crystalline phase and an increase of the fragility index $\mathrm{D}$, so that undercooled liquids with equivalent onset driving forces can have different glass forming abilities. The combination of low onset driving forces, high solid/liquid interfacial energy and 'strong' liquid behaviour (high liquid fragility index D) results in better glass forming ability of alloys in the $\mathrm{CaMg}_{2}$ precipitation phase field and with compositions near $\mathrm{Ca}_{60} \mathrm{Mg}_{20} \mathrm{Zn}_{20}$. This provides the first general analytic approach for identifying the best glass forming compositions across broad compositional regimes spanning more than one primary crystalline phase in metallic glasses.

\section{Acknowledgements}

The authors acknowledge help of Mr. J.M. Scott in the alloy preparation. Financial support from the United States Air Force Office of Scientific Research through Research Task 01ML05-COR (Dr. J. Tiley, Program Manager) is greatly appreciated. 


\section{$\underline{\text { References }}$}

1. O.N. Senkov, J.M. Scott, in: MRS Proceedings, Vol. 806 (Materials Research Society, Warrendale, PA, 2003) pp. 145-150.

2. O.N. Senkov, J.M. Scott, Scripta Mater. 50 (2004) 449-452.

3. O.N. Senkov, J.M. Scott, Materials Letters 58 (2004) 1375-1378.

4. E.S. Park, D.H. Kim, J. Mater. Research 19 (2004) 685-688.

5. E.S. Park, W.T. Kim, D.H. Kim, Mater. Sci. Forum 475-479 (2005) 3415-3418.

6. O.N. Senkov and J.M. Scott, J. Non-Cryst. Solids 351 (2005) 3087-3094.

7. M.L. Morrison, R.A. Buchanan, O.N. Senkov, D.B. Miracle, P.K. Liaw, Electrochemical Behavior of Ca-based Bulk Metallic Glasses, Metall. Mater. Trans. A (2005).

8. A. Inoue, Acta Mater. 48 (2000) 279-306.

9. A. Zhu, G.J. Shiflet, D.B. Miracle, Scripta Mater. 50 (2004) 987-991.

10. A. Zhu, S.J. Poon, G.J. Shiflet, Scripta Mater. 50 (2004) 987.

11. T. Tokunaga, H. Ohtani, M. Hasebe, CALPHAD 28 (2004) 354.

12. R.E. Hackenberg, M.C. Gao, L. Kaufman, G.J. Shiflet, Acta Mater. 50 (2002) 2245.

13. G.J. Fan, H.-J. Fecht, J. Chem. Phys. 116 (2002) 5002.

14. H. Tanaka, J. Non-Cryst. Solids 351 (2005) 678.

15. R. Bormann, Mater. Sci. Eng. A178 (1994) 55.

16. N. Mattern, J. Eckert U. Kuhn, H. Hermann, J. Sakawski, G. Herms, J. Neuefeind, Appl. Phys. Lett. 80 (2002) 4525.

17. K. Saksl, H. Franz, P. Jovari, K. Klementiev, E. Welter, A. Ehnes, J. Saida, A. Inoue, J.Z. Jiang, Appl. Phys. Lett. 83 (2003) 3924.

18. M. Palumbo, G. Cacciamani, E. Bosco, M. Baricco, CALPHAD 25 (2001) 625. 
19. J. Agren, B. Cheynet, M.T. Clavaguera-Mora, K. Hack, J. Hertz, F. Sommer, U. Kattner, CALPHAD 19 (1995) 449.

20. A.T. Dinsdale, CALPHAD 15 (1991) 317.

21. C.O. Brubaker and Z.-K. Liu, J. Alloys \& Compounds 370 (2004) 114-122.

22. C.A. Angell, Science 267 (1995) 1924.

23. D.B. Miracle, Nature Mater. 3 (2004) 697.

24. L. Kaufman, H. Bernstein, Computer Calculation of Phase Diagrams, Academic Press, New York, 1970.

25. B. Sundman, J. Agren, J. Phys. Chem. Solids 42 (1981) 297-301.

26. M. Hillert, Phase Equilibria, Phase Diagrams and Phase Transformations, Cambridge University Press 1998, 151.

27. D. Kim, B.J. Lee, N.J. Kim, Intermetallics, 12 (2004) 1103-1107.

28. D. Kim, B.-J. Lee, N.J. Kim, Scripta Mater., 52 (2005) 969-972.

29. X. Gu, G.J. Shiflet, F.Q. Guo and S.J. Poon, J. Mater. Res., 20 (2005) 1935-1938.

30. K. Mondal, B.S. Murty, J. Non-Cryst. Solids, 351 (2005) 1366-1371.

31. D. Turnbull, Comtemp. Phys. 10 (1969) 473.

32. Z.P. Lu, C.T. Liu, Acta Mater., 50 (2002) 3501-3512.

33. A. Inoue, T. Zhang, T. Masumoto, J. Non-Cryst. Solids, 156-158 (1993) 473.

34. D. Turnbull, J Appl. Phys., 21 (1950) 1022-1028.

35. D.B. Miracle, W.S. Sanders, O.N. Senkov, Philos. Mag. A 83 (2003) 2409.

36. D.B. Miracle, O.N. Senkov, W.S. Sanders and K.L. Kendig Mat. Sci. Eng. A, A375-377 (2004) 150-156.

37. T. Egami and Y. Waseda, J. Non-Cryst. Solids 64 (1984) 113.

38. O.N. Senkov and D.B. Miracle, Mater. Res. Bull. 36 (2001) 2183. 
39. H.J. Lee, T. Cagin, W.L. Johnson, W.A. Goddard, J. Chem. Phys. 119 (2003) 9858.

40. H. Tanaka, J. Phys.: Condens. Matter. 15 (2003) L491.

41. R. Busch, E. Bakke, W.L. Johnson, Acta Mater. 46 (1998) 4725.

42. Z.P. Lu, Y. Li, C.T. Liu, J. Appl. Phys. 93 (2003) 286. 


\section{$\underline{\text { Tables }}$}

Table 1. Critical thickness, $\lambda$, glass transition, $T_{g}$, crystallization, $T_{x}$, melting, $T_{m}$, and liquidus, $T_{1}$, temperatures, $\alpha\left(T_{x} / T_{l}\right), \mathrm{T}_{\mathrm{rgx}}\left(T_{g} T_{x} / T_{l} T_{m}\right), \Delta \mathrm{T}_{\mathrm{xg}}\left(T_{x}-T_{g}\right)$ and onset driving force (ODF) for crystallization at $\mathrm{T}=390 \mathrm{~K}$ for $\mathrm{Ca}-\mathrm{Mg}-\mathrm{Zn}$ metallic glasses.

\begin{tabular}{lccccccccc}
\hline \hline Alloy & $\begin{array}{c}\lambda \\
(\mathrm{mm})\end{array}$ & $\begin{array}{c}\mathrm{T}_{\mathrm{g}} \\
(\mathrm{K})\end{array}$ & $\begin{array}{c}\mathrm{T}_{\mathrm{x}} \\
(\mathrm{K})\end{array}$ & $\begin{array}{c}\mathrm{T}_{\mathrm{m}} \\
(\mathrm{K})\end{array}$ & $\begin{array}{c}\mathrm{T}_{1} \\
(\mathrm{~K})\end{array}$ & $\alpha$ & $\mathrm{T}_{\text {rgx }}$ & $\Delta \mathrm{T}_{\mathrm{xg}}$ & $\begin{array}{c}\mathrm{ODF} / \\
\mathrm{RT}\end{array}$ \\
\hline $\mathrm{Ca}_{55} \mathrm{Mg}_{15} \mathrm{Zn}_{30}$ & 0.5 & 389 & 419 & 623 & 711 & 0.589 & 0.368 & 30 & 1.18 \\
$\mathrm{Ca}_{55} \mathrm{Mg}_{20} \mathrm{Zn}_{25}$ & 2 & 383 & 428 & 623 & 702 & 0.610 & 0.375 & 45 & 1.07 \\
$\mathrm{Ca}_{55} \mathrm{Mg}_{25} \mathrm{Zn}_{20}$ & 1 & 375 & 418 & 609 & 751 & 0.557 & 0.343 & 43 & 1.47 \\
$\mathrm{Ca}_{60} \mathrm{Mg}_{10} \mathrm{Zn}_{30}$ & 0.5 & 380 & 425 & 623 & 710 & 0.599 & 0.365 & 45 & 1.24 \\
$\mathrm{Ca}_{60} \mathrm{Mg}_{15} \mathrm{Zn}_{25}$ & 6 & 379 & 427 & 609 & 650 & 0.657 & 0.409 & 48 & 1.03 \\
$\mathrm{Ca}_{60} \mathrm{Mg}_{17.5} \mathrm{Zn}_{22.5}$ & 10 & 378 & 428 & 609 & 650 & 0.658 & 0.409 & 50 & 0.89 \\
$\mathrm{Ca}_{60} \mathrm{Mg}_{20} \mathrm{Zn}_{20}$ & 4 & 378 & 415 & 609 & 660 & 0.629 & 0.390 & 37 & 1.10 \\
$\mathrm{Ca}_{60} \mathrm{Mg}_{25} \mathrm{Zn}_{15}$ & 1 & 377 & 409 & 609 & 744 & 0.550 & 0.340 & 32 & 1.51 \\
$\mathrm{Ca}_{62.5} \mathrm{Mg}_{17.5} \mathrm{Zn}_{20}$ & 10 & 375 & 412 & 609 & 640 & 0.644 & 0.396 & 37 & 0.81 \\
$\mathrm{Ca}_{65} \mathrm{Mg}_{15} \mathrm{Zn}_{20}$ & 6 & 375 & 410 & 609 & 630 & 0.651 & 0.401 & 35 & 0.86 \\
$\mathrm{Ca}_{70} \mathrm{Mg}_{10} \mathrm{Zn}_{20}$ & 0.5 & 367 & 399 & 609 & 657 & 0.607 & 0.366 & 32 & 0.93 \\
\hline \hline
\end{tabular}

Table 2. Critical thickness $\lambda$, critical cooling rate $\mathrm{R}_{\mathrm{c}}$ calculated from $\lambda$ using equations given in [32], and fragility index D calculated from Equation 5. The GFA parameters $\gamma\left(T_{x} /\left(T_{g}+T_{l}\right)\right)$ and $\mathrm{T}_{\mathrm{rg}}\left(T_{g} / T_{l}\right)$ used for the calculations of $\mathrm{R}_{\mathrm{c}}$ and $\mathrm{D}$ are also tabulated here.

\begin{tabular}{lccccc}
\hline \hline Alloy & $\begin{array}{c}\lambda \\
(\mathrm{mm})\end{array}$ & $\gamma$ & $\mathrm{T}_{\mathrm{rg}}$ & $\begin{array}{c}\mathrm{R}_{\mathrm{c}} \\
(\mathrm{K} / \mathrm{s})\end{array}$ & $\mathrm{D}$ \\
\hline $\mathrm{Ca}_{55} \mathrm{Mg}_{15} \mathrm{Zn}_{30}$ & 0.5 & 0.381 & 0.547 & 13740 & 14 \\
$\mathrm{Ca}_{55} \mathrm{Mg}_{20} \mathrm{Zn}_{25}$ & 2 & 0.394 & 0.546 & 279 & 20 \\
$\mathrm{Ca}_{55} \mathrm{Mg}_{25} \mathrm{Zn}_{20}$ & 1 & 0.371 & 0.499 & 1960 & 25 \\
$\mathrm{Ca}_{60} \mathrm{Mg}_{10} \mathrm{Zn}_{30}$ & 0.5 & 0.390 & 0.535 & 13740 & 16 \\
$\mathrm{Ca}_{60} \mathrm{Mg}_{15} \mathrm{Zn}_{25}$ & 6 & 0.415 & 0.583 & 13 & 19 \\
$\mathrm{Ca}_{60} \mathrm{Mg}_{17.5} \mathrm{Zn}_{22.5}$ & 10 & 0.416 & 0.582 & 3 & 22 \\
$\mathrm{Ca}_{60} \mathrm{Mg}_{20} \mathrm{Zn}_{20}$ & 4 & 0.400 & 0.573 & 40 & 19 \\
$\mathrm{Ca}_{60} \mathrm{Mg}_{25} \mathrm{Zn}_{15}$ & 1 & 0.365 & 0.507 & 1960 & 24 \\
$\mathrm{Ca}_{62.5} \mathrm{Mg}_{17.5} \mathrm{Zn}_{20}$ & 10 & 0.406 & 0.586 & 3 & 21 \\
$\mathrm{Ca}_{65} \mathrm{Mg}_{15} \mathrm{Zn}_{20}$ & 6 & 0.408 & 0.595 & 13 & 17 \\
$\mathrm{Ca}_{70} \mathrm{Mg}_{10} \mathrm{Zn}_{20}$ & 0.5 & 0.390 & 0.559 & 13740 & 12 \\
\hline \hline
\end{tabular}




\section{Appendix}

Table A1: Thermodynamic description of the Ca-Mg-Zn liquid phase from Brubaker et al [21].

Sublattice model Parameters (S.I. units)

${ }^{0} L_{C a, M g}^{L}=-32322.4+16.7211 \cdot T$
${ }^{1} L_{C a, M g}^{L}=+60.3+6.549 \cdot T$
${ }^{2} L_{C a, M g}^{L}=-5742.3+2.7596 \cdot T$
${ }^{0} L_{C a, Z n}^{L}=-65435+10.624 \cdot T$
${ }^{1} L_{C a, Z n}^{L}=-+43288-12.978 \cdot T$
${ }^{2} L_{C a, Z n}^{L}=-49709+35.547 \cdot T$
${ }^{0} L_{M g, Z n}^{L}=-81439+518.25 \cdot T$
${ }^{1} L_{M g, Z n}^{L}=+2627.54+2.93061 \cdot T$
${ }^{2} L_{M g, Z n}^{L}=-1673.28$
${ }^{0} L_{C a, M g, Z n}^{L}=-7029.7$
${ }^{1} L_{C a, M g, Z n}^{L}=-47787$
${ }^{2} L_{C a, M g, Z n}^{L}=-5437.5$




\section{Figures}

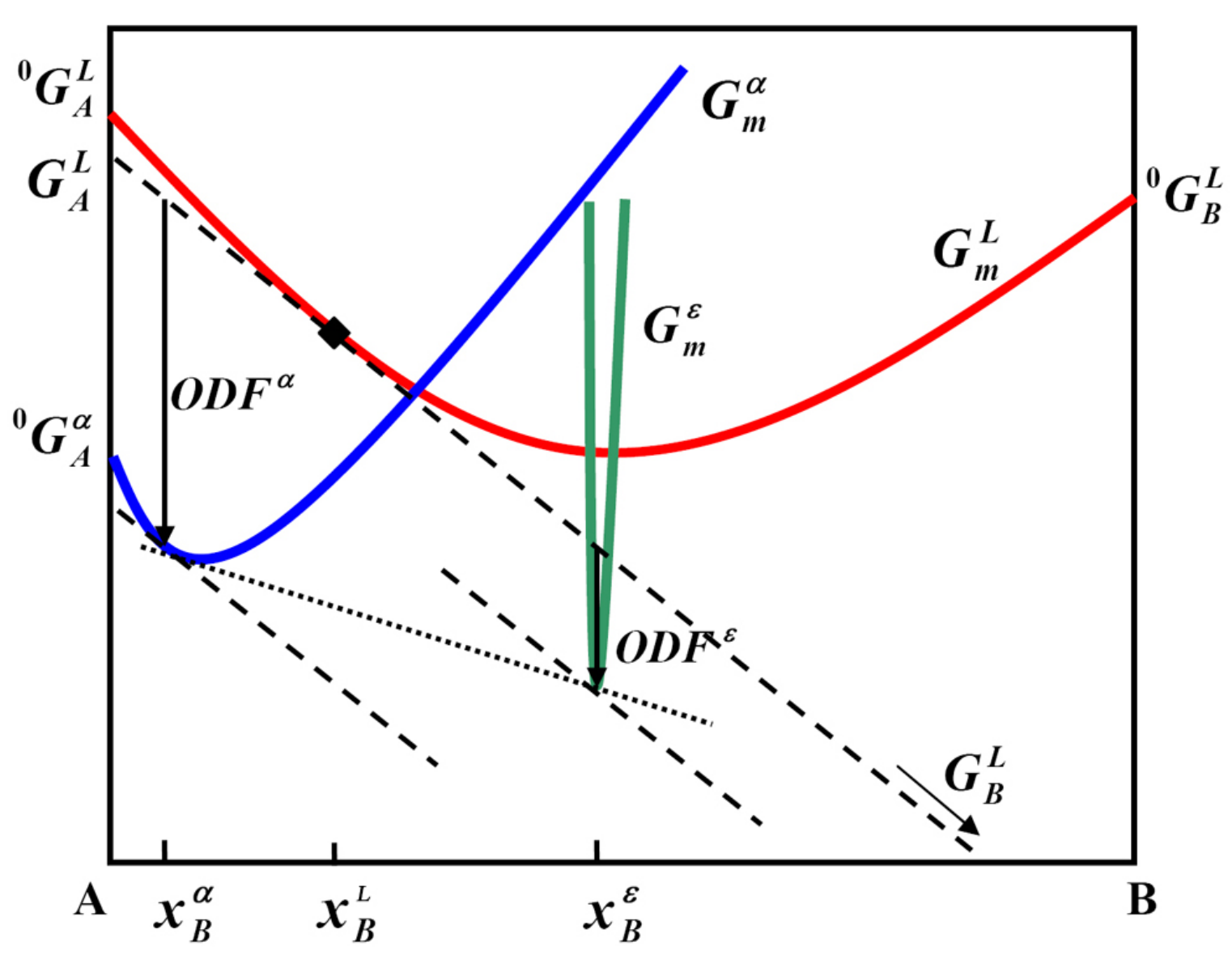

Figure 1: Molar Gibbs energy diagram illustrating the method to calculate onset driving forces for the beginning of the precipitation of two new phases $\alpha$ (solid solution) and $\varepsilon$ (line-compound) from an undercooled liquid for the composition $x_{B}^{L}$. The dotted line represents the common tangent (equilibrium), and the dashed lines show the tangents to the Gibbs energy curve of the liquid phase at the composition $x_{B}^{L}$, and to the Gibbs energy curve of $\alpha$ at the composition $x_{B}^{\alpha}$. $G_{A}^{L}$ and $G_{B}^{L}$ are the chemical potentials of $\mathrm{A}$ and $\mathrm{B}$ atoms, respectively, in the liquid phase of composition $x_{B}^{L}$ and at the temperature T. Vertical arrows represent the onset driving forces for the precipitation of $\alpha\left(\mathrm{ODF}^{\alpha}\right)$ and $\varepsilon\left(\mathrm{ODF}^{\varepsilon}\right)$, respectively. 


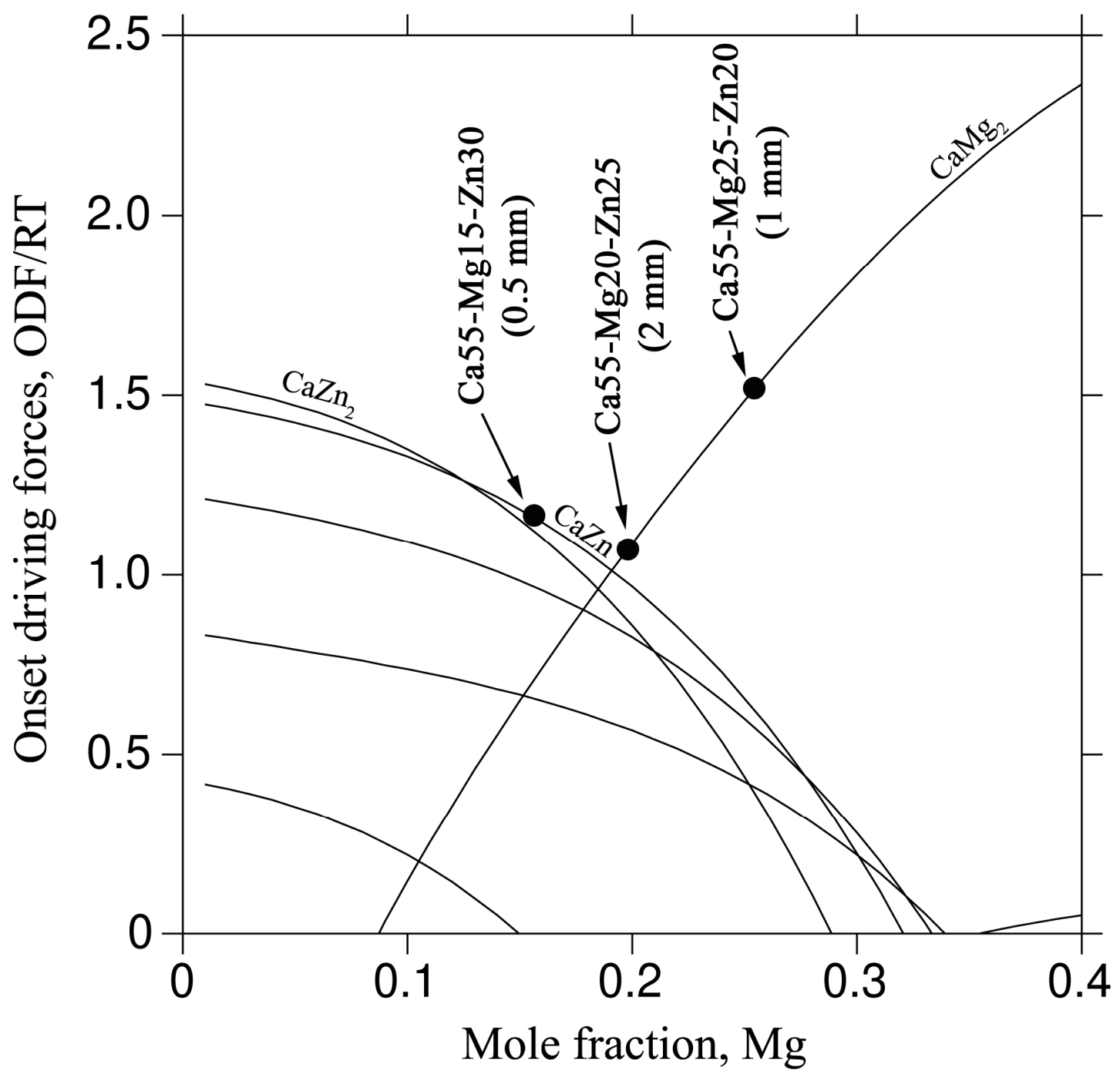

Figure 2: Calculated onset driving forces of various crystalline phases for $\mathrm{Ca}_{55} \mathrm{Mg}_{\mathrm{x}} \mathrm{Zn}_{100-\mathrm{x}}$ alloys versus $\mathrm{Mg}$ content at $390 \mathrm{~K}$. The circles represent the alloy compositions studied. Their critical thicknesses are indicated. 


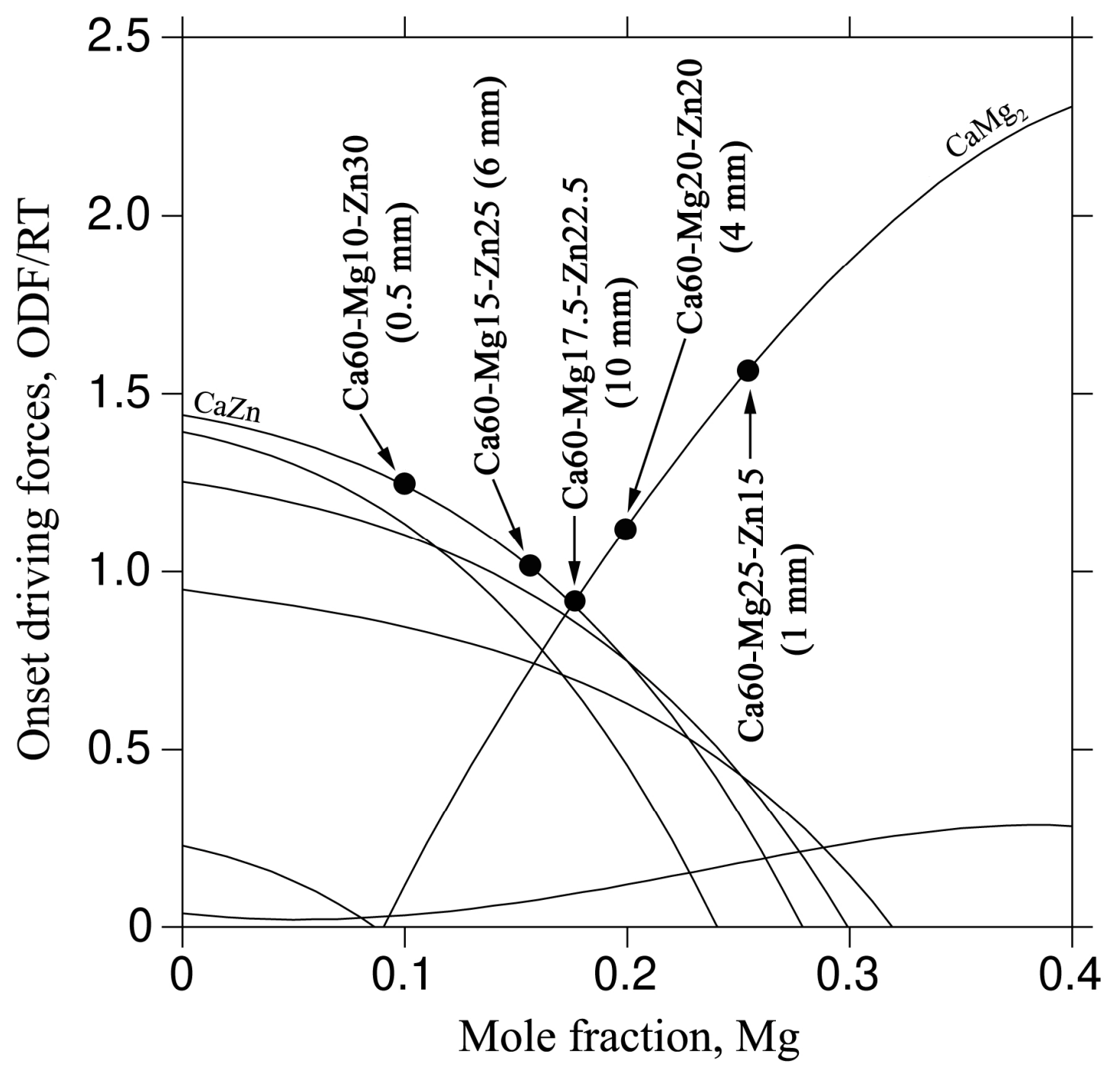

Figure 3: Calculated onset driving forces of various crystalline phases for $\mathrm{Ca}_{60} \mathrm{Mg}_{\mathrm{x}} \mathrm{Zn}_{100-\mathrm{x}}$ alloys versus $\mathrm{Mg}$ content at $390 \mathrm{~K}$. The circles represent the alloy compositions studied. Their critical thicknesses are indicated. 


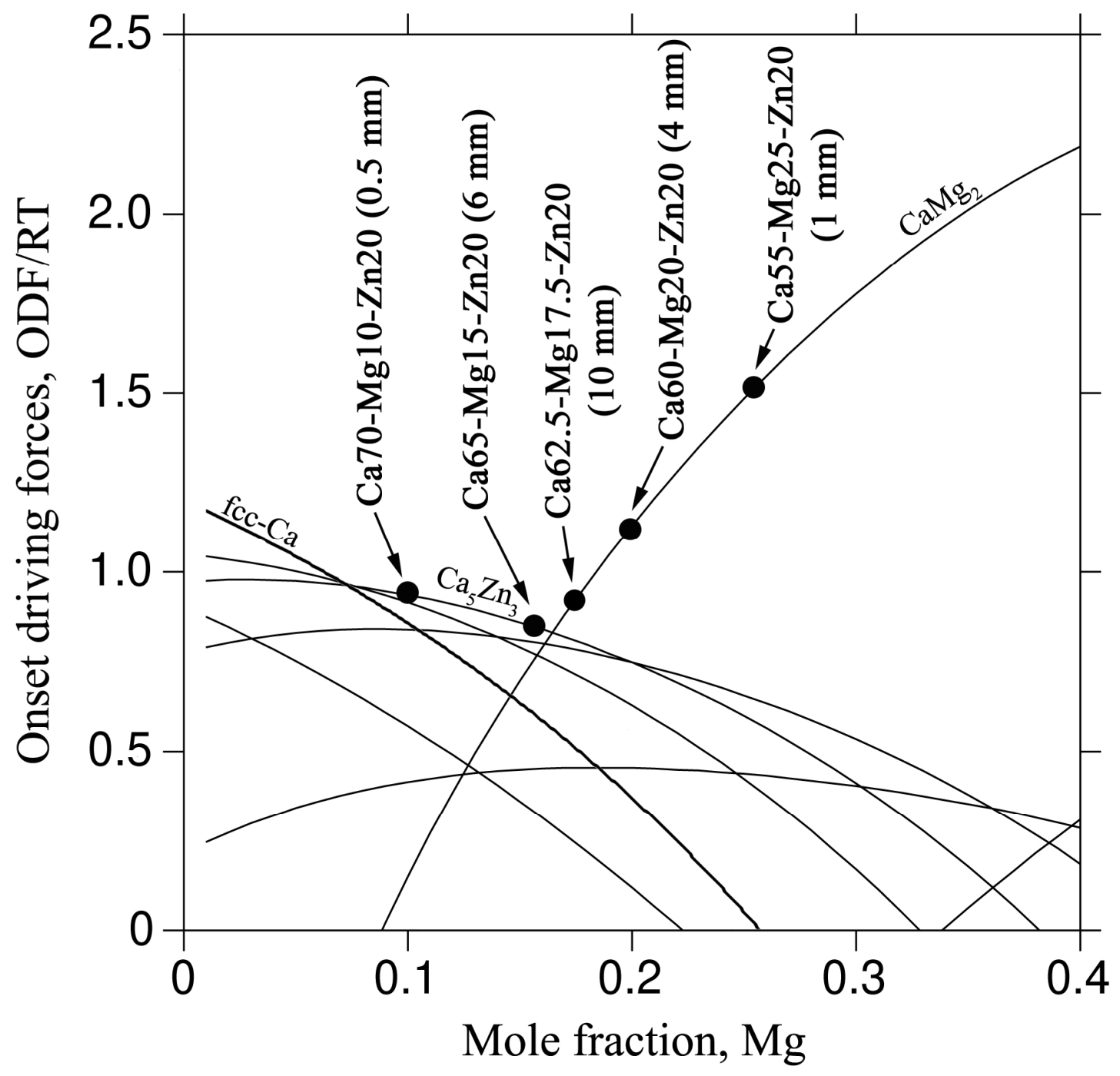

Figure 4: Calculated onset driving forces of various crystalline phases for $\mathrm{Ca}_{(100-\mathrm{x})} \mathrm{Mg}_{\mathrm{x}} \mathrm{Zn}_{20}$ alloys versus $\mathrm{Mg}$ content at $390 \mathrm{~K}$. The circles represent the alloy compositions studied. Their critical thicknesses are indicated. 


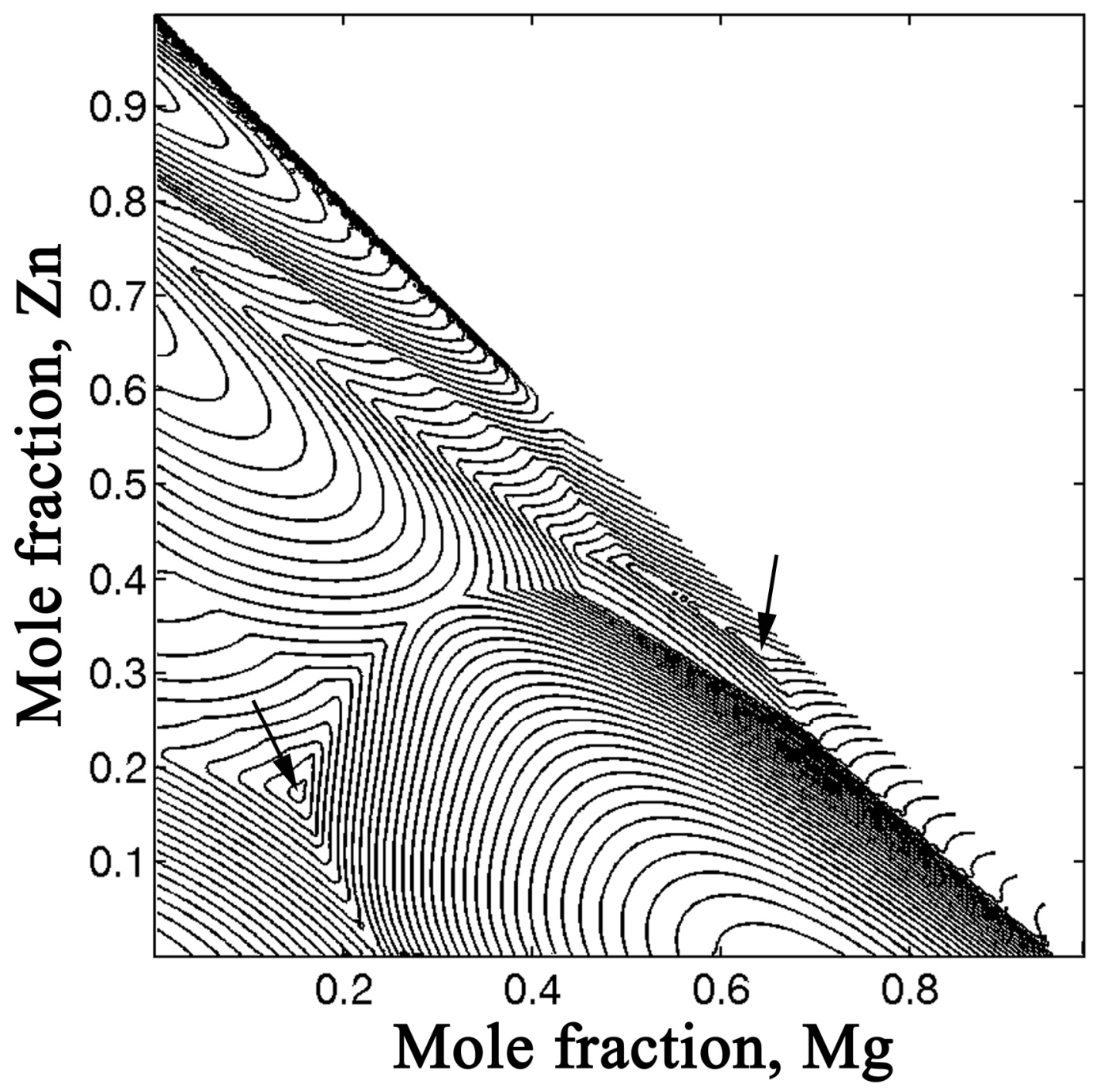

Figure 5: Complete two-dimensional plot of the onset driving forces (ODF) calculated for the full composition space in the Ca-Mg-Zn system at $390 \mathrm{~K}$. The two ODF minima are identified by arrows. 


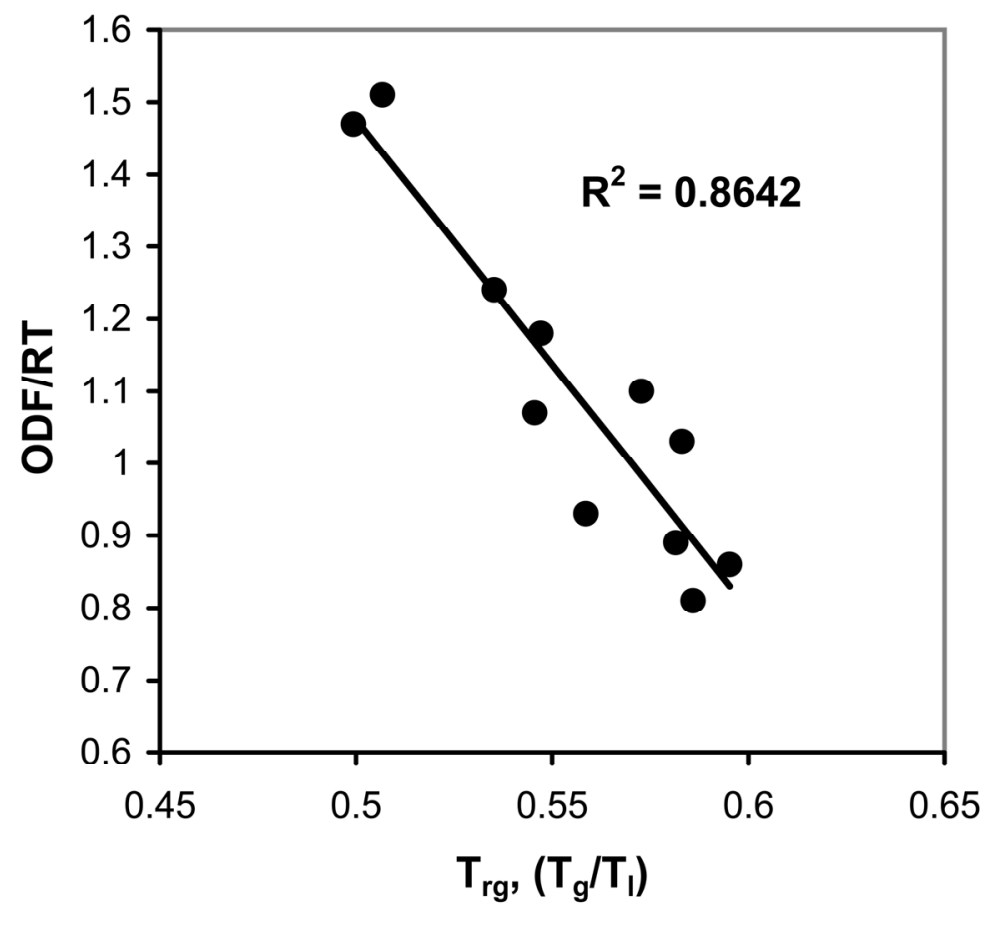

(a)

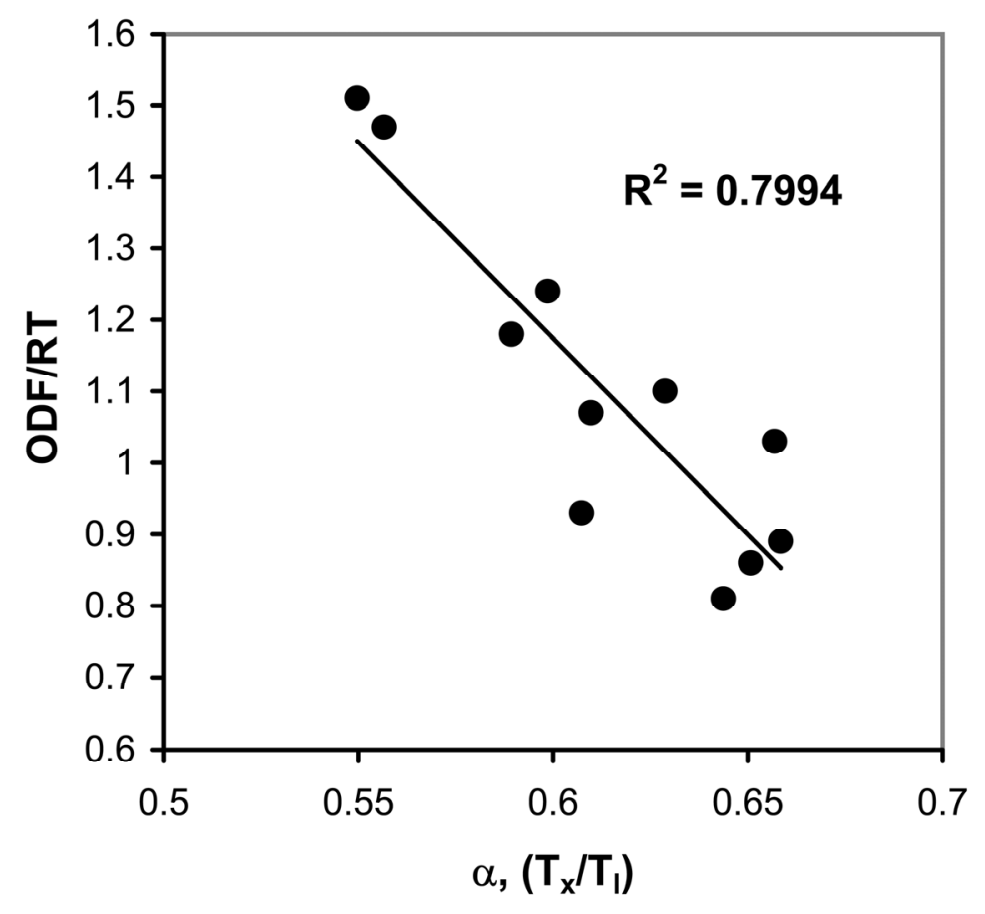

(b) 


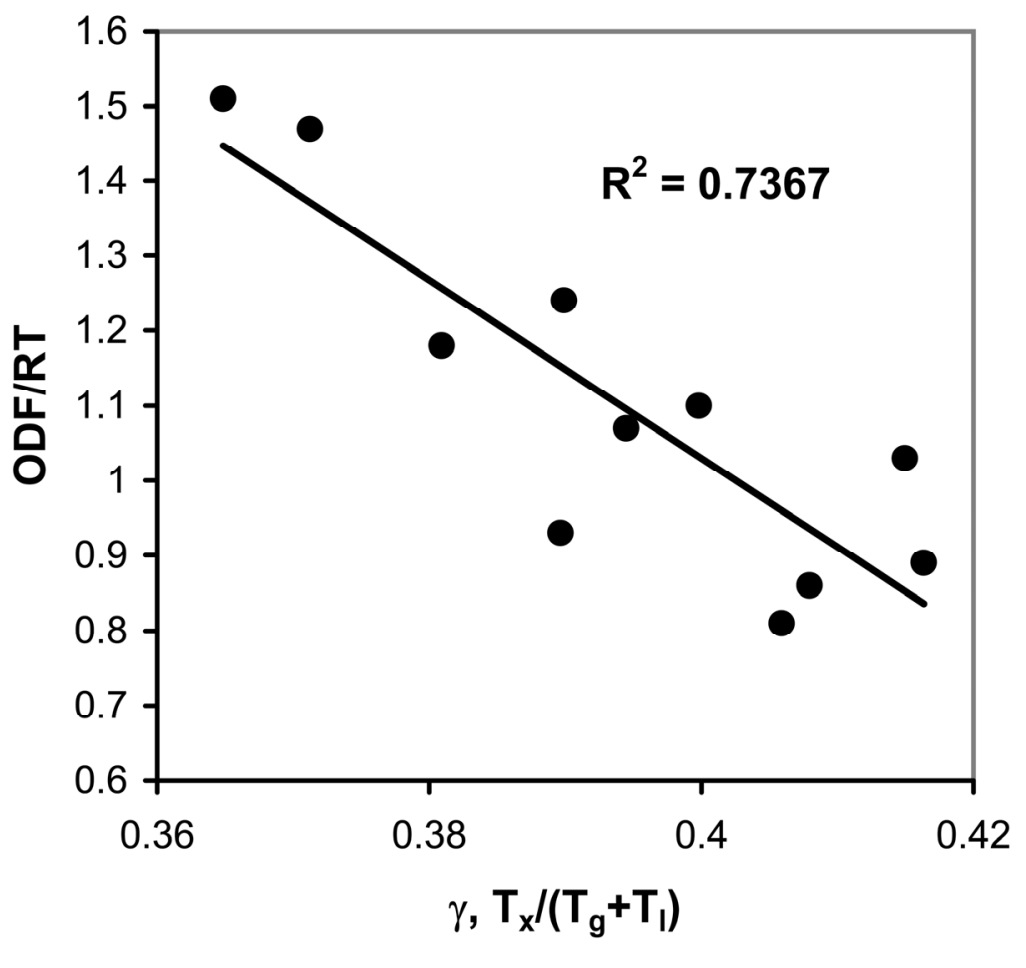

(c)

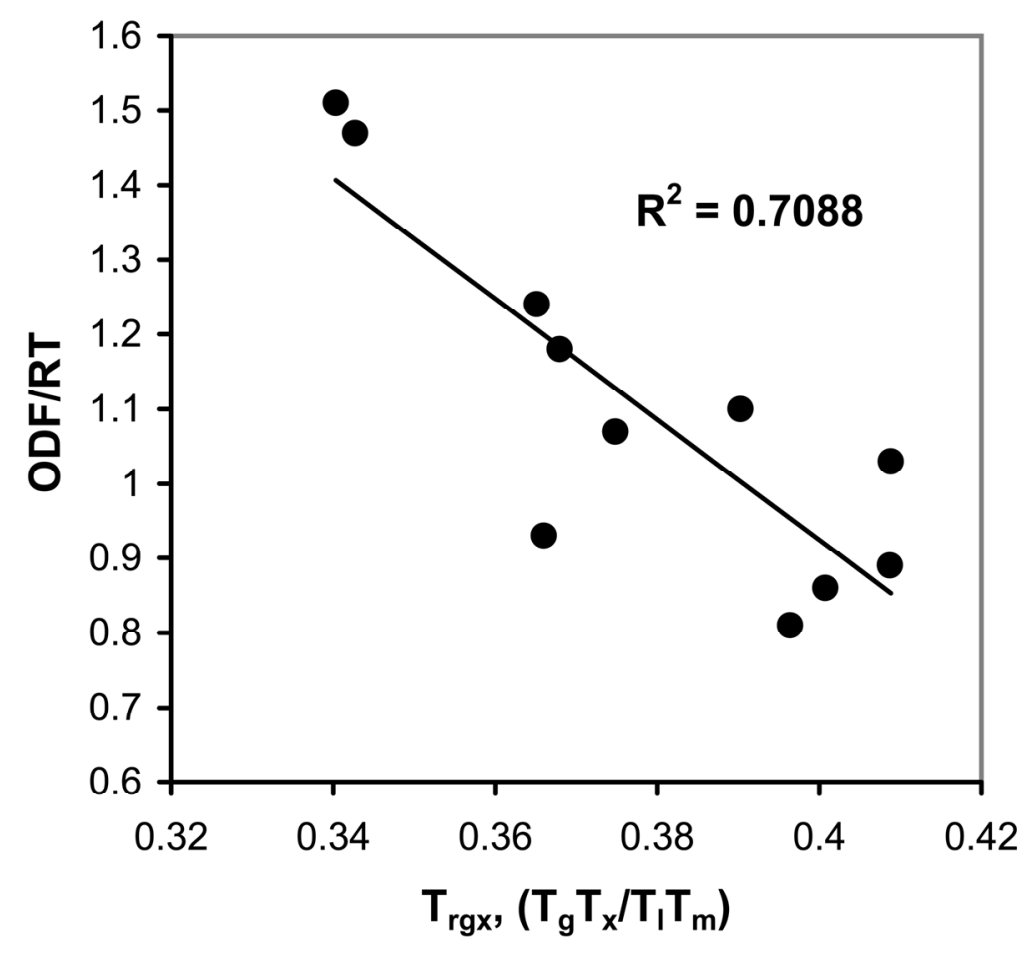




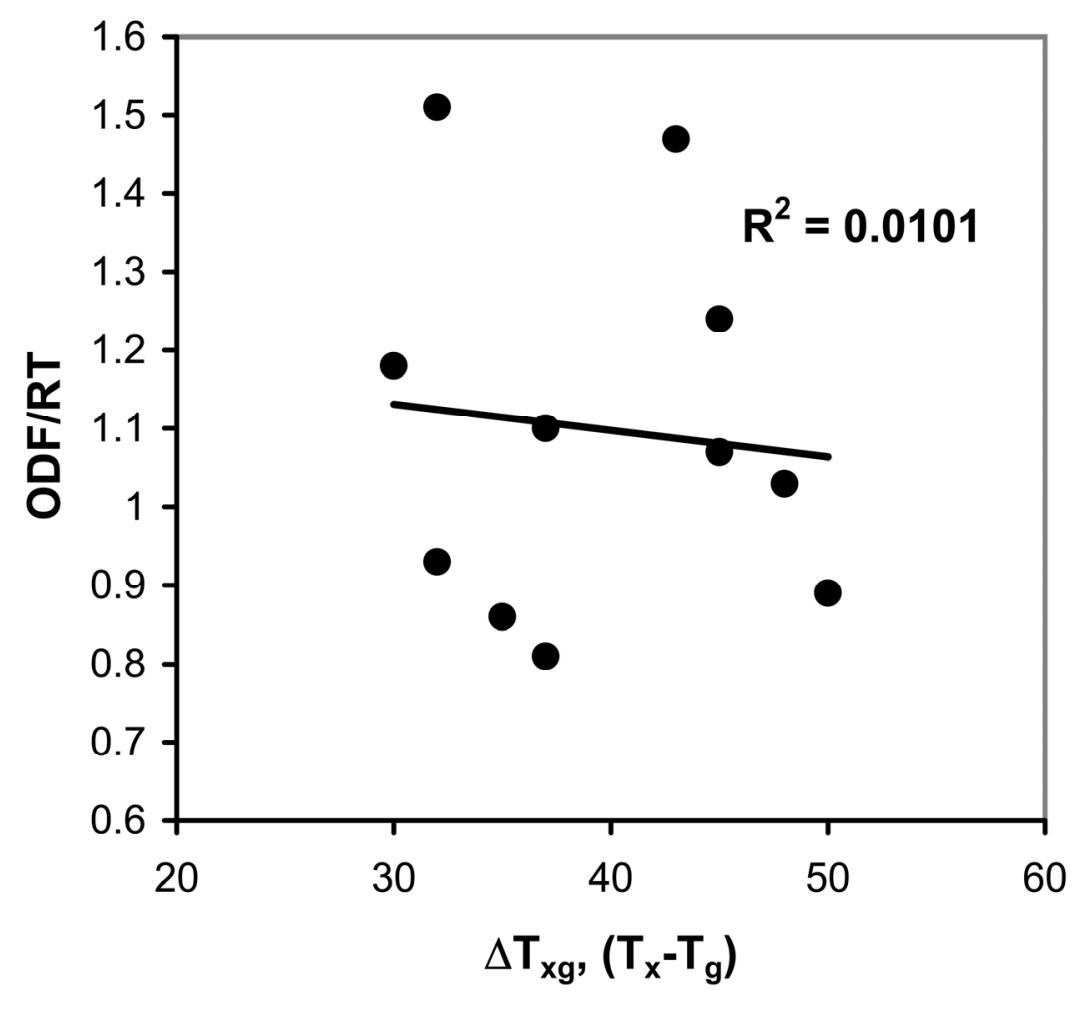

Figure 6: Correlation between ODF and GFA indicators (a) $T_{r g}=T_{g} / T_{l}$, (b) $\alpha=T_{x} / T_{l}$, (c) $\gamma=T_{x} /\left(T_{g}+T_{l}\right)$, (d) $T_{r g x}=T_{g} T_{x} / T_{l} T_{m}$ and (e) $\Delta T_{x g}=T_{x}-T_{g}$ for $11 \mathrm{Ca}-\mathrm{Mg}-\mathrm{Zn}$ alloys given in Table 1 . The trendlines and corresponding regression coefficients $\left(\mathrm{R}^{2}\right)$ are shown. 


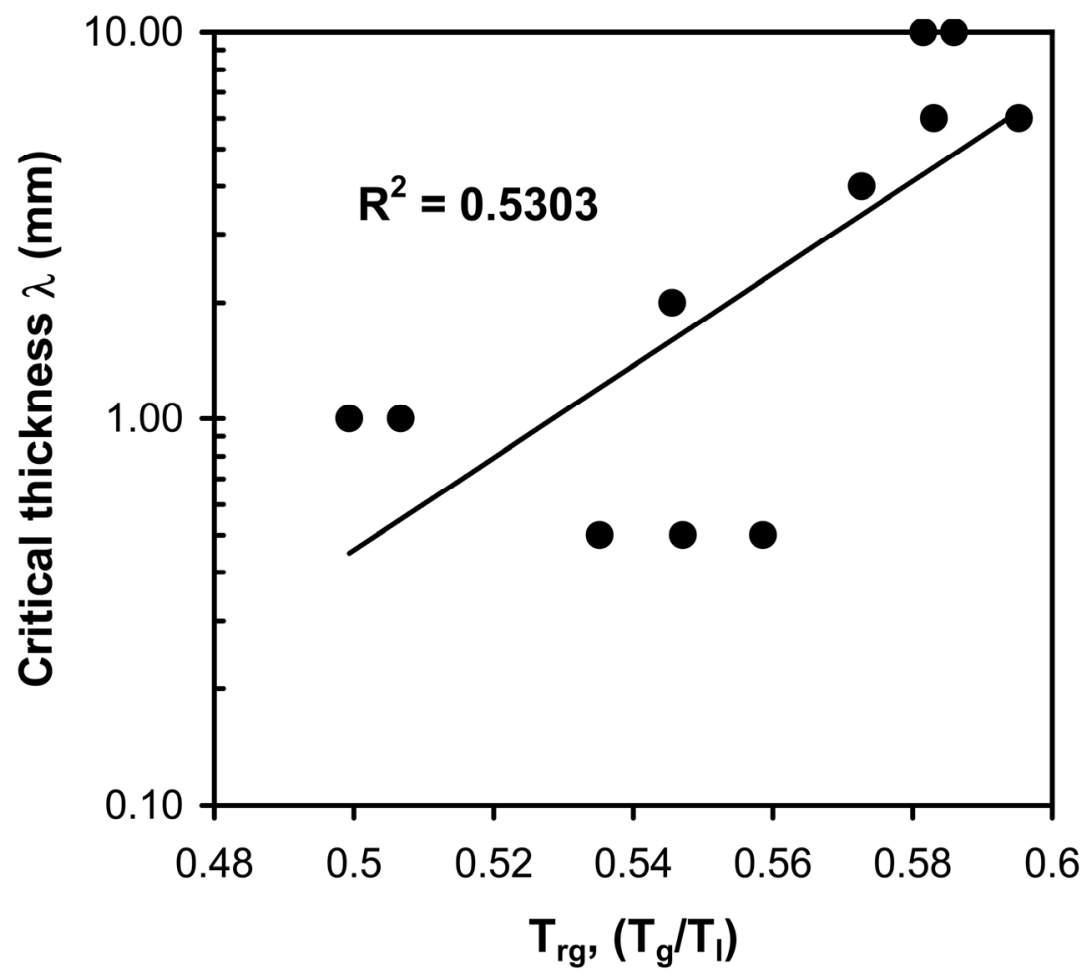

(a)

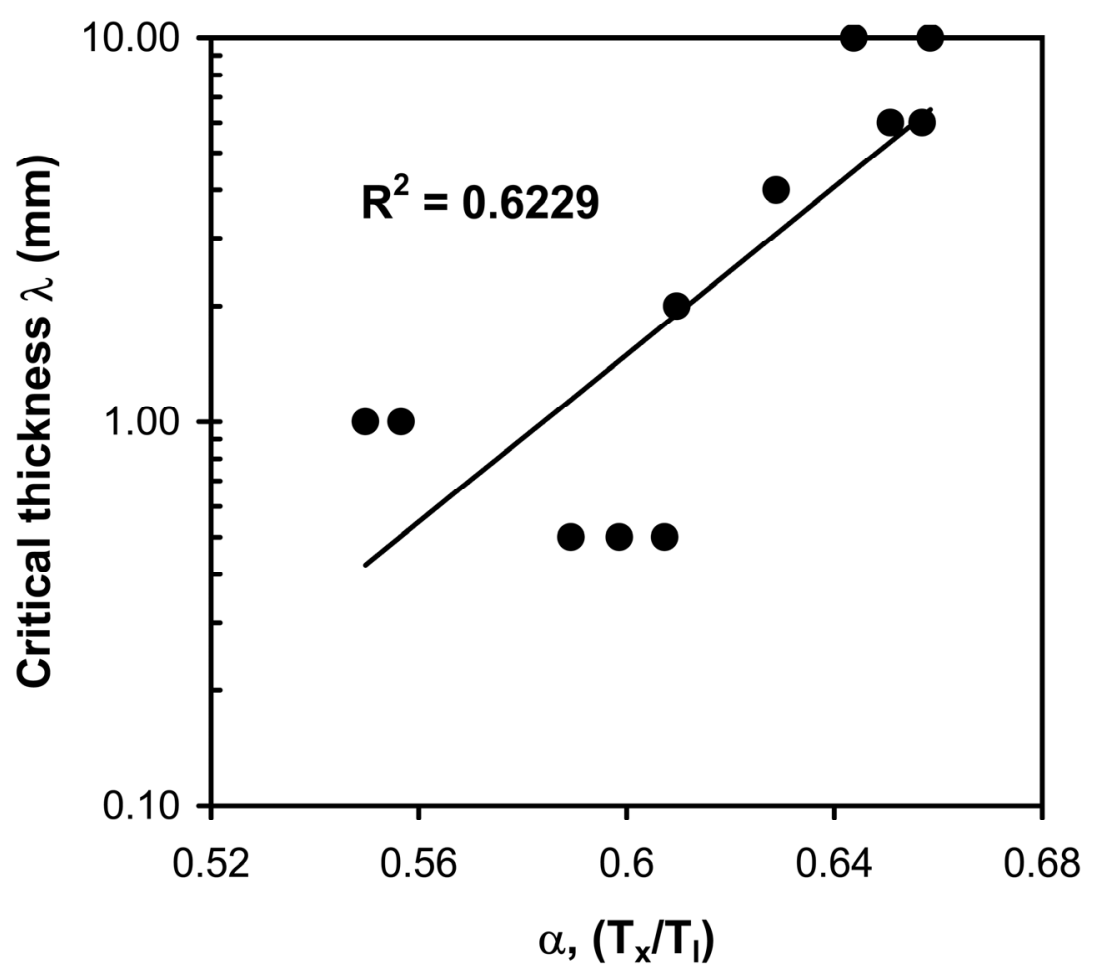




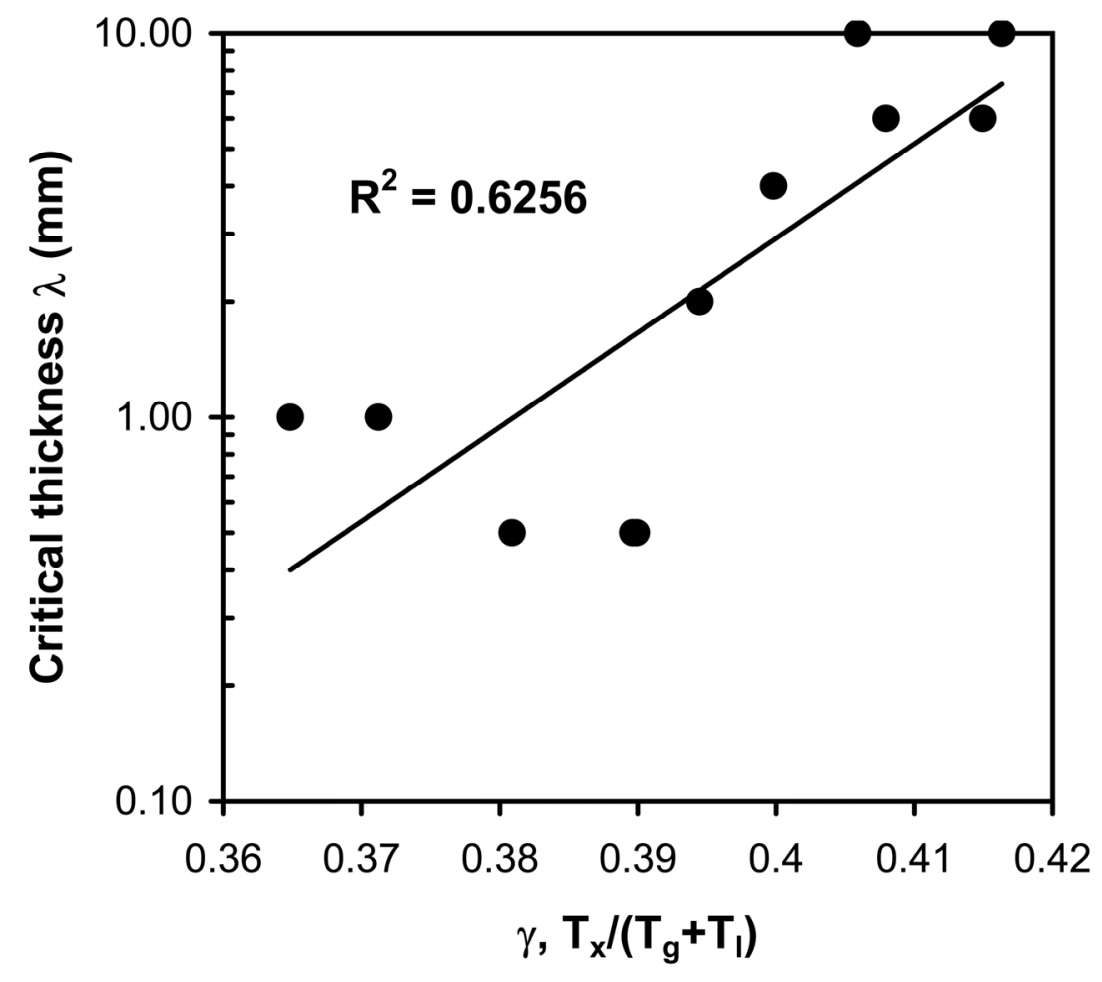

(c)

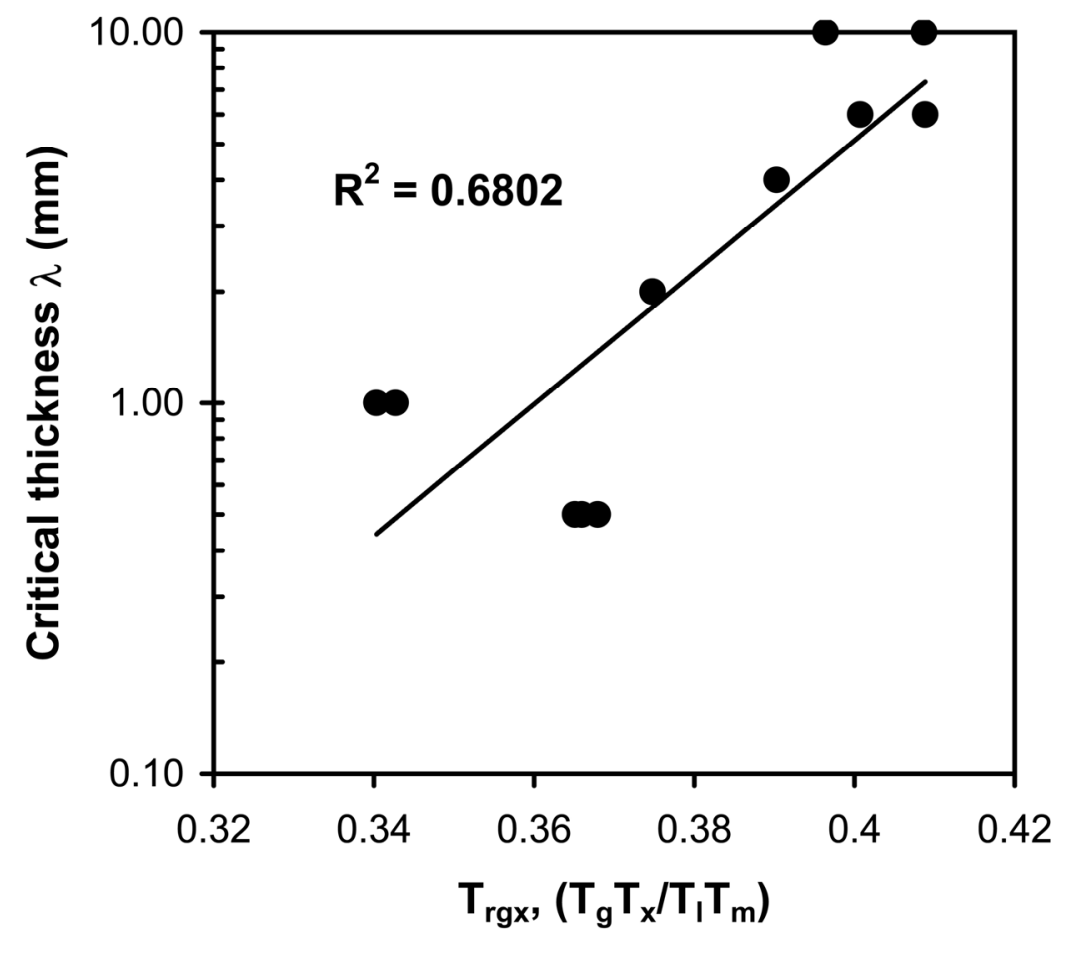




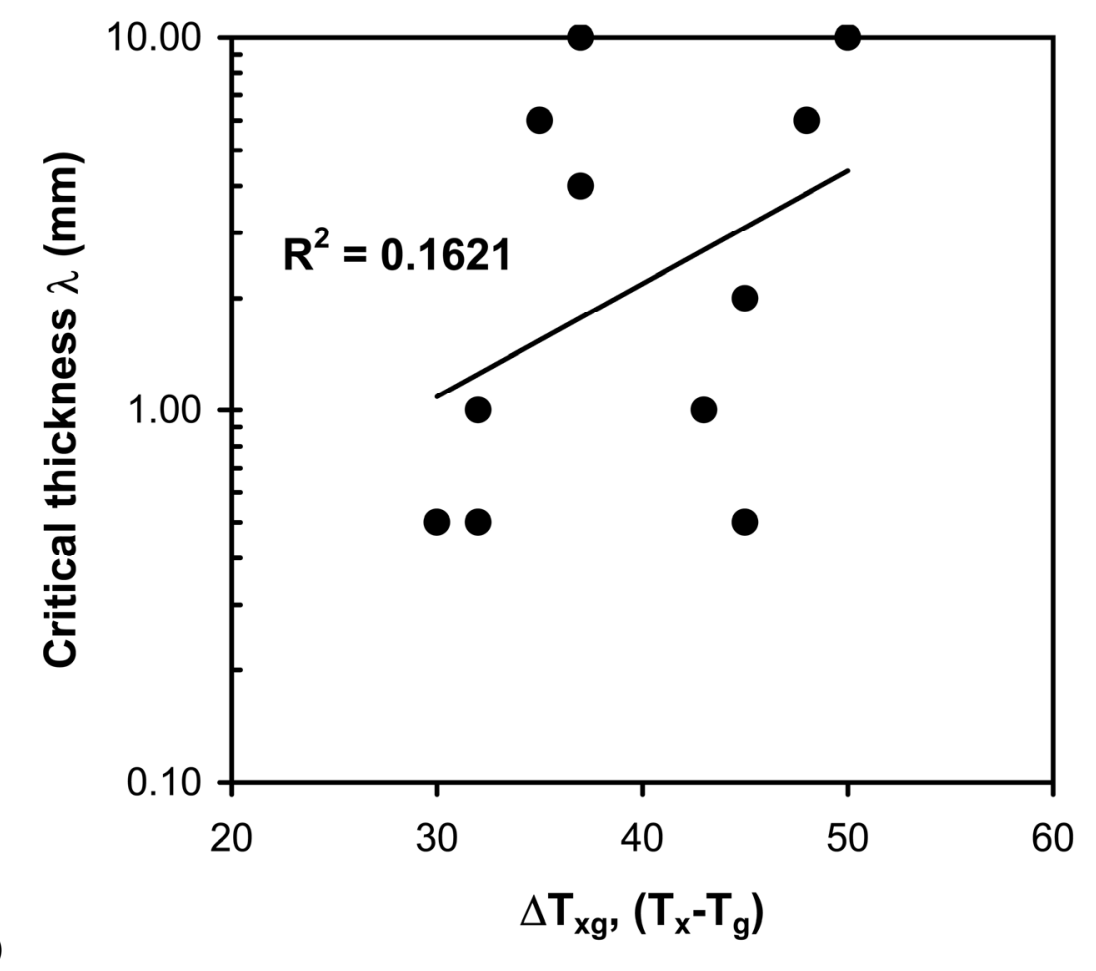

Figure 7: Correlation between the critical thickness $(\lambda)$ and GFA indicators (a) $T_{r g}=T_{g} / T_{l}$, (b) $\alpha=T_{x} / T_{l}$, (c) $\gamma=T_{x} /\left(T_{g}+T_{l}\right)$, (d) $T_{r g x}=T_{g} T_{x} / T_{l} T_{m}$ and (e) $\Delta T_{x g}=T_{x}-T_{g}$ for $11 \mathrm{Ca}-\mathrm{Mg}-\mathrm{Zn}$ alloys given in Table 1. The trendlines and corresponding regression coefficients $\left(\mathrm{R}^{2}\right)$ are shown. 

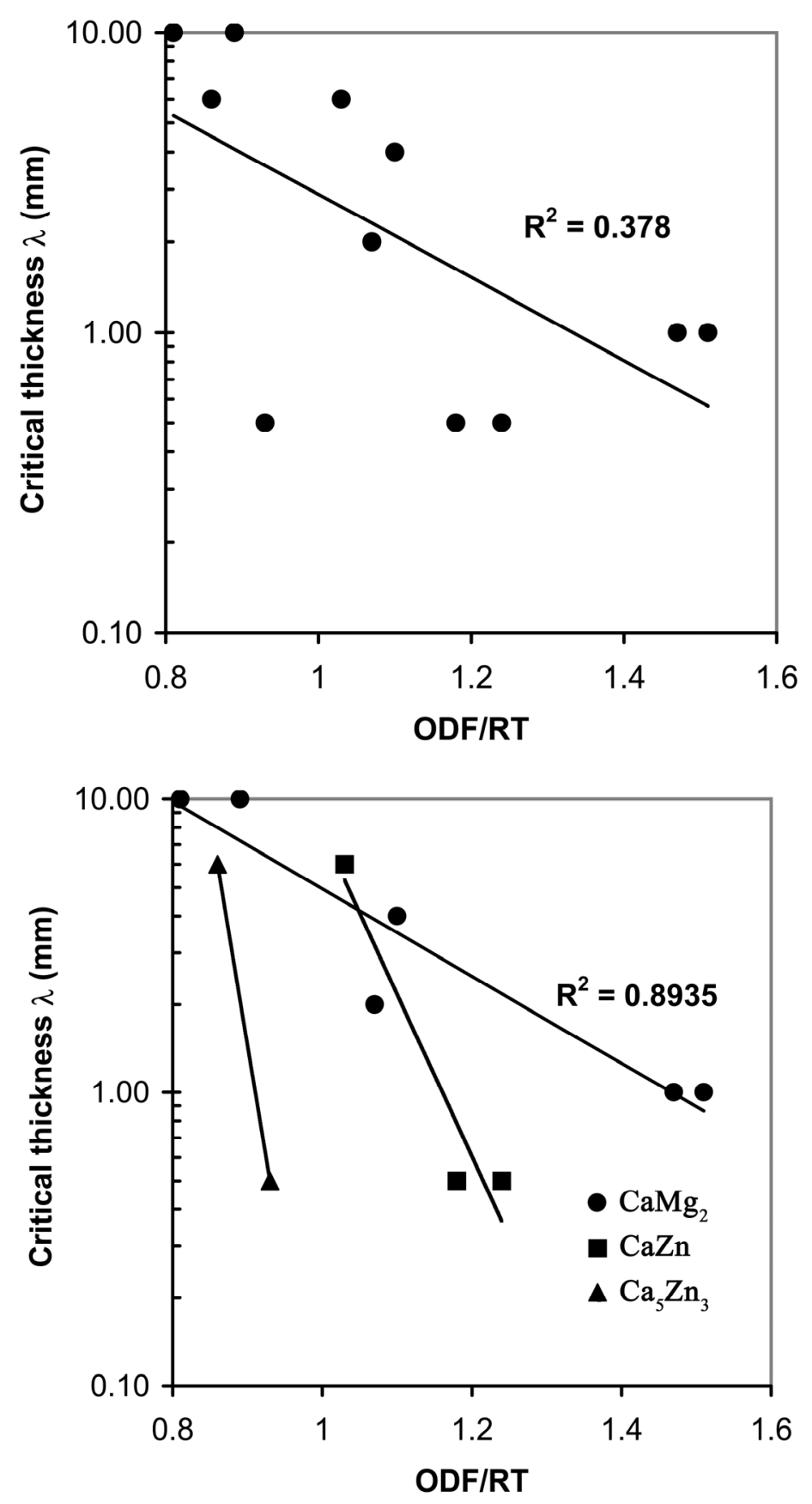

Figure 8: (a) Correlation between the critical thicknesses $(\lambda)$ and the calculated onset driving force normalized by the gas constant $\mathrm{R}$ and absolute temperature $\mathrm{T}(\mathrm{ODF} / \mathrm{RT})$ for $11 \mathrm{Ca}-\mathrm{Mg}-\mathrm{Zn}$ alloys given in Table 1. (b) The same data set arrayed into three groups, with alloys forming $\mathrm{CaMg}_{2}\left(1^{\text {st }}\right.$ group$), \mathrm{CaZn}$ ( $2^{\text {nd }}$ group) and $\mathrm{Ca}_{5} \mathrm{Zn}_{3}$ ( ${ }^{\text {rd }}$ group) phases during the onset of crystallization of the undercooled liquid (see Figures 1-3). 


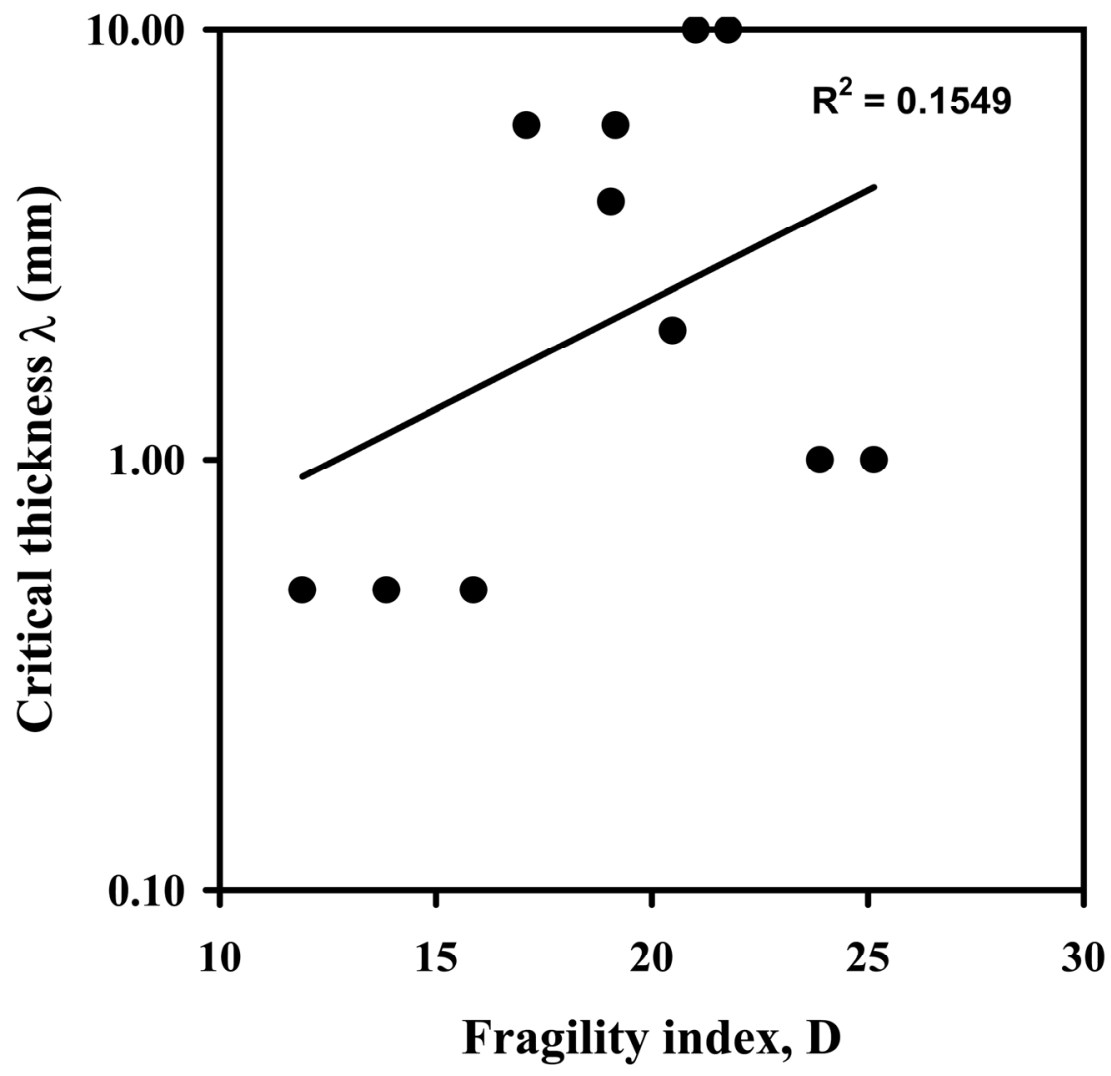

Figure 9: Correlation between the critical thickness $(\lambda)$ and the fragility index D. The trendline and corresponding regression coefficients $\left(\mathrm{R}^{2}\right)$ are shown. 


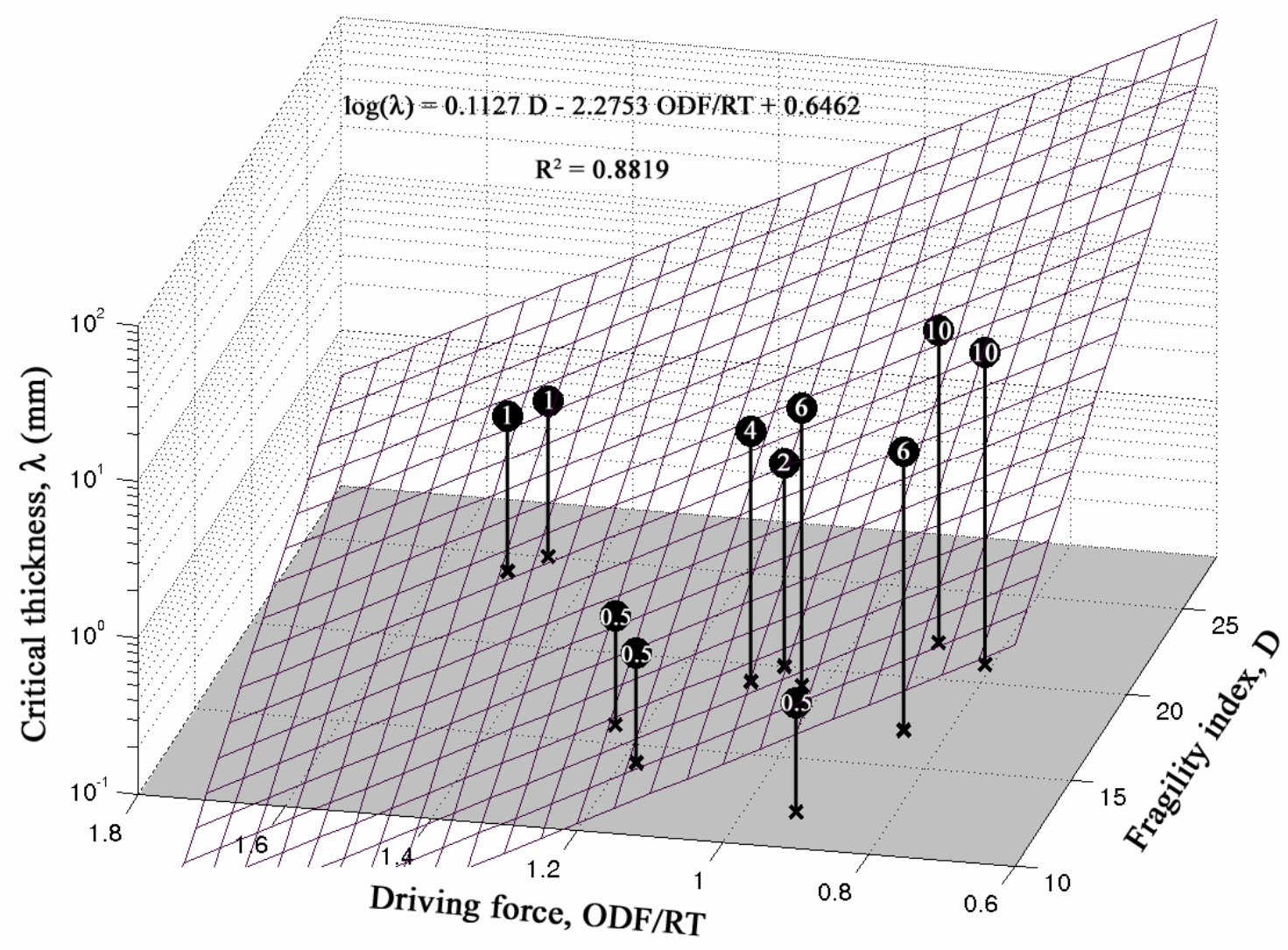

Figure 10: Correlation between the critical thickness $(\lambda)$, the fragility index D and the calculated onset driving force normalized by the gas constant $\mathrm{R}$ and absolute temperature $\mathrm{T}$ (ODF/RT) for $11 \mathrm{Ca}-\mathrm{Mg}-\mathrm{Zn}$ alloys given in Table 1 and Table 2. Values of the critical thicknesses are indicated in millimeters in the black sphere for each alloy composition. The data are well fitted by the meshed plane drawn. Its equation and regression coefficient are also shown. 